\title{
Observations of forest stand top height and mean height from interferometric SAR and LIDAR over a conifer plantation at Thetford Forest, UK
}

\section{HEIKO BALZTER ${ }^{1}$, ADRIAN LUCKMAN ${ }^{2}$, LAINE SKINNER ${ }^{2}$, CLARE ROWLAND ${ }^{3}$, TERRY DAWSON $^{4}$}

\author{
${ }^{I}$ Climate and Land Surface Systems Interactions Centre(CLASSIC), Department of Geography, University of Leicester, \\ University Road, Leicester, LE1 7RH, UK, Email: hb91@le.ac.uk \\ ${ }^{2}$ Dept. of Geography, University of Wales Swansea, SA2 8PP, UK \\ ${ }^{3}$ Centre for Ecology and Hydrology (CEH), Section for Earth Observation, Monks Wood, Abbots Ripton, Cambridgeshire, \\ PE28 2LS, UK \\ ${ }^{4}$ Centre for Environmental Change and Sustainability, University of Edinburgh, Mayfield Road, EH9 3JK
}

\begin{abstract}
Estimates of forest stand mean height using airborne LiDAR (Light Detection And Ranging) instruments have been previously reported with accuracies comparable to traditional ground-based measurements. However, the small area covered by a LiDAR sensor in a single aircraft overpass is a significant hindrance for large scale forest inventories. In comparison, airborne interferometric Synthetic Aperture Radar (InSAR) systems are also able to make estimates of surface height, but the swath coverage is often far greater, typically five or ten times that of the LiDAR coverage. A set of interferometric data takes was acquired by the ESAR airborne sensor over a managed pine plantation at Thetford Forest, UK. Scattering phase centre height estimates were made from two single-pass X-band acquisitions and polarimetric repeat-pass L-band acquisitions and compared with height estimates made from a separate LiDAR acquisition. The relationship between the scattering phase centre heights and stand top height is described, and the accuracy of stand top height estimates estimated from InSAR and LiDAR is quantified by the root mean square error (rmse). General yield class models by the Forestry Commission (UK) were used to estimate stand top height from a GIS database used for forest management.

The longer wavelength L-band radiation penetrates deeper into the canopy than X-band and the scattering phase centre height is affected by both forest structural parameters (canopy density, understorey and gaps) and sensor parameters (look-angle and reduced coherence through temporal and volume decorrelation). Consequently, a simple translation of scattering phase centre height into stand top height gives noisy results for L-band, with observed rmse values between $\pm 3.1 \mathrm{~m}$ in the near range and $\pm 6.4 \mathrm{~m}$ in the far range. The X-band based top height estimates are more accurate with rmse between $\pm 2.9 \mathrm{~m}$ in the near and $\pm 4.1 \mathrm{~m}$ in the far range, which can be further reduced by an empirical incidence angle correction. Stand top height estimates from LiDAR achieved an rmse of only $\pm 2.0 \mathrm{~m}$.

The X-band scattering phase centre heights have also been related to mean stand height and are comparable with heights observed from the LiDAR sensor and field measurements. An rmse of $\pm 2.5 \mathrm{~m}$ for the mean stand height estimates based the X-band data set was found. Finally, we briefly discuss error propagation from the use of a terrain model, here provided by the Ordnance Survey.
\end{abstract}

\section{Introduction}


Over the past two decades, the use of Airborne Laser Scanning techniques in forest mensuration practices has developed from a research base (Nelson et al., 1984) into an ongoing commercial application (Baltsavias, 1999). A number of key forest parameters, such as mean stand height, stand basal area and stand volume may be derived from LiDAR data sets with an accuracy similar to, or even better than, conventional methods (Naesset, 2004). As a result, a growing number of commercial LiDAR sensors is now available. In 2001, 75 organizations world-wide were operating 60 systems (Holmgren et al., 2003a).

Beyond forest management applications, remote sensing techniques have potential to inform the scientific community about forest conditions crucial to the understanding of sustainable land use. Keller et al. (2004) found that in the Amazon rain forest, edges and logged forests are susceptible to fire, and that positive feedback cycles of forest degradation may be initiated by land-use-change events. Nepstad et al. (1999) state the importance of Amazonian deforestation rates for determining human effects on the global carbon cycle. Measuring forest conditions can contribute to a better understanding of forest impoverishment.

However, for applications such as forest inventory, a limiting factor when using LiDAR data is the relatively small area imaged by the sensor in each overpass. The swath width from a small-footprint LiDAR sensor is typically only a few hundred meters across and multiple flight-lines must be flown to cover even a moderately sized forest plantation (e.g. Holmgren et al., 2003b). In contrast, interferometric airborne radar (InSAR) sensors are capable of being operated over a larger incidence angle range and at a higher altitude. Consequently, the swath width is typically 10 times larger than that of a typical LiDAR survey.

Encouraging results on the retrieval of forest height from repeat-pass SAR interferometry have been reported for a number of sensors: JERS-1 (Dammert and Wegmüller, 1999), ERS-1 (Dammert et al., 1995), ERS-1/2 Tandem mission (Floury et al., 1996, Santoro et al., 2003, Hyyppä and Engdahl, 2000) and E-SAR (Hoekman and Varekamp, 2001). Single-pass interferometric SAR studies have also investigated the retrieval of height, e.g. using TOPSAR (Kobayashi et al., 2000, Treuhaft and Siquiera, 2000).

Furthermore, Papathanassiou and Cloude (2001) and Skinner et al. (2002) report measurements of forest height with accuracies similar (in some test cases) to the previously mentioned LiDAR results. Backscatter and coherence information may also be derived as part of the InSAR product and have previously been used to estimate forest parameters such as biomass density and stand volume (e.g. LeToan et al., 1992, Askne et al., 1997, Santoro et al., 2000, Tansey et al., 2004). Polarimetric SAR interferometry has been shown to give good tree height estimates (Papathanassiou et al., 2003, Cloude and Corr, 2003). Single-pass airborne interferometric sensors are able to provide complementary information in a single system. However, the accuracy of forest canopy height derived from scattering phase centre heights requires careful consideration.

The main goal of this study is to quantify the accuracy of the retrievals of stand top height and mean stand height from SAR interferometry (images taken by the airborne ESAR sensor operated by the German Space Agency DLR) and LiDAR (image taken by Environment Agency) at Thetford forest. The effects of sensor related parameters (e.g. incidence angle and wavelength) and forest related parameters (e.g. canopy gap fraction, stand age and stand structure) on the scattering phase centre height estimates are also discussed.

The results are then compared with current mensuration techniques used at Thetford Forest (UK) and also compared with LiDAR measurements made over the same forest stands. The following definitions are needed to distinguish different height terms used in the manuscript: Forest canopy height is the height of the highest vegetation components above the ground level, mean stand height is the mean canopy height of a forest stand, tree height is the height of the tip of the stem of an individual tree, top height of a forest stand is the "average height of a number of 'top height trees' in a stand, where a 'top height tree' is the largest breast height diameter in a 0.01 ha sample plot" (Edwards, 1981, p. 18) and the interferometric 
scattering phase centre height from SAR interferometry (InSAR) is the vertical location within the canopy from which most of the backscatter signal is coming.

\section{Test Site}

Thetford Forest is located in East Anglia, UK $\left(52.5^{\circ} \mathrm{N}, 0.5^{\circ} \mathrm{E}\right), 45 \mathrm{~km}$ west of Norwich. The main forest covers an area of approximately $20 \mathrm{~km}$ x $30 \mathrm{~km}$ which comprises around $25 \%$ of the Breckland area (Ratcliffe and Harris, 1996). Topography is very flat, with only minor gentle terrain differences. Most of Thetford forest is managed by clear fell rotation, but small parts are mixed-age stands. Plantations are $85 \%$ conifers, 9\% mixed woods and 6\% broadleaves. Main species (source: Forestry Commission GIS, 1990) are Corsican Pine (54\%) and Scots Pine (31\%) with Beech (4\%), Oak (3\%), Douglas Fir (2\%), and Birch, Poplar, and Larch (1\% each). The site is managed by the UK Forestry Commission (FC) who is responsible for the maintenance of each stand including planting, clearing and thinning strategies. In general, the forest stands tend to be uniform in structure, contain little understorey and dead wood components with a clear delineation of the stand boundaries. Trees tend to be planted in rows. Figure 1 shows photographs of a 16 and a 34 year old Corsican Pine stand at Thetford forest.

\section{1 Forestry Commission GIS and Yield Class Models}

The main source of information used to manage Thetford forest is a polygon-based GIS database containing several thousand forest compartments (management units), which generally because of their differences in tree age, species and soil quality represent biophysically different forest stands. Associated with each polygon is an attribute database providing information on the stand age since planting, species composition, a stand factor indicating productivity of the stand and a yield class. Further information concerning the soil type, productivity, rotation and other parameters, is also held in the database. Figure 2 shows a thematic map of the stand age in the main forest area at Thetford and the E-SAR X-band backscatter image. The age range of stands varies from less than 6 years to greater than 70 years with the majority of stands aged between 20 and 30 years. Because Corsican pine stands show a good age variation these are the focus of this study. Most Scots Pine stands tend to be of old age, because of a change in the Forestry Commission's planting policy.

Further forest parameters may be estimated from the stand age information when combined with published yield class models (Edwards, 1981). These models describe empirically derived allometric functions for five main variables: stand top height, mean diameter at breast height, total stand mass, stand volume and stand dry matter. The functions vary depending on the yield class of each stand which is defined at an early stage of the stand development and based upon its future commercial value. Figure $3 \mathrm{a}$ shows the yield class functions relating top height to stand age. The increase in the growth profile for different yield classes is clearly shown. Typical accuracies published by the FC indicate that the yield models may be used to predict forest parameters to within $20 \%$ of the actual value for relatively evenaged managed monocultures (Edwards, 1981). According to Edwards (1981) typical tree densities for Corsican Pine (main crop after thinning, spacing $1.4 \mathrm{~m}$, intermediate thinning regime) are decreasing from 3860 to 208 trees per hectare (yield class 20) for stands aged 13 to 78 years, from 3900 to 291 trees per hectare (yield class 14) for stands aged 16 to 81 years, and from 3887 to 414 trees per hectare (yield class 10) for stands aged 20 to 80 years. In Figure $3 \mathrm{~b}$ the fractional canopy cover from a nadir position derived from field measurements is shown as a function of stand age. Figure $3 \mathrm{c}$ gives an example of the mean stand height for yield class 14, modelled as the top height weighted by the fractional canopy cover, as a function of stand age.

Independent field measurements at Thetford Forest were made during the JPL/Maestro-1 campaign (Mitchell, 1989) and Thetford ground campaign (Skinner and Luckman, 2000), termed ThetfordGC from this point onward. Results from the two field campaigns confirm the accuracy statistics quoted for the top height yield model (rmse for top height of $\pm 2.24 \mathrm{~m}$ and $\pm 1.41 \mathrm{~m}$ were calculated in each case respectively). The top height measurements made during the ThetfordGC are overlaid on Figure 3a. 


\subsection{Relating Mean Stand Height to Top Height}

The mean height of a forest stand, as derived from a nadir looking position, is not often used in forest management and mensuration practices at Thetford; top height is the more common parameter. However, the mean height of the main scattering elements in a resolution cell is being retrieved by a radar sensor. The InSAR scattering phase centre height estimate over each resolution cell is a combination of all the scattering components within the cell volume. This may include the tree top, the edge of a tree crown, undergrowth, tree trunks and/or a ground contribution. Mean stand height needs to be translated into top height, if remote sensing techniques are to be used for forest management. It will be advantageous to define an empirical solution to allow a conversion between the two parameters.

$$
\begin{aligned}
& F=\frac{N \cdot A}{10000} \\
& M=F \cdot T
\end{aligned}
$$

where $\mathrm{N}=$ number of trees per hectare, $\mathrm{A}=$ mean area of 1 tree crown $\left(\mathrm{m}^{2}\right), \mathrm{F}=$ fractional canopy coverage from a nadir viewing position, $\mathrm{T}=$ yield class estimate for stand top height $(\mathrm{m}), \mathrm{M}=$ mean stand height $(\mathrm{m})$.

The yield class model estimates for stocking density $N$ and crown area $A$ were used to calculate the fractional canopy coverage $F$ in Equation 1. This value was then used to weight the yield class estimate for top height $T$ to derive the mean stand height $M$ in Equation 2. Field measurements made during the ThetfordGC were also used to assess the accuracy of the yield class models. Tree spacing, crown dimensions and tree height were recorded in 48 plots within various aged stands throughout Thetford Forest. The full results are reported in Skinner et al. (2002) and are comparable with the official accuracy statistics for the yield class models.

The modelled fractional canopy cover for three common yield classes is shown in Figure $3 b$. Interestingly, lower fractional values (i.e. larger canopy gaps) occur in stands with a higher yield class, the reason being that stands with a higher yield class tend to have higher intensity thinning programs to promote the growth of larger trunks. Consequently, the lower number of trees in the higher yield class stands result in increased gaps between neighbouring tree crowns.

The mean stand height for yield class 14 is plotted in Figure 3c. Similar results for the other yield classes are also found. The effects of gaps in the forest canopy are observed for stands younger than 15 years and older than 30 years. The planting distance between individual trees at Thetford is typically larger than the crown diameter of young trees. Significant gaps in the forest canopy exist in these younger stands but are later reduced when neighbouring tree crowns grow larger and ultimately merge together. Thinning programs at Thetford (initiated in stands aged between 20 and 30 years) then cause significant gaps in the canopy as whole rows are removed. The mean height of the stand will reflect these changes whereas the top height will not.

\section{Digital Surface Model (DSM) Generation \\ 3.1 InSAR Data}

The ESAR sensor is an experimental airborne SAR system developed by the German Aerospace Centre (DLR). Three separate flights were made over Thetford Forest in June 2000 covering an area of $8 \mathrm{~km} \mathrm{x} 5$ $\mathrm{km}$ in each overpass (the X-band backscatter image is shown in Figure 4). The data acquired included:

i) two X-band datasets in single-pass interferometric mode at vertical transmit and receive polarisation

ii) two L-band fully polarimetric data sets acquired in separate flights with a 15 minute temporal baseline and a spatial baseline of approximately $10 \mathrm{~m}$ 
Pre-processing of the ESAR data was completed by DLR and BAE Systems. Pairs of single look complex images were then made available for the X-band and fully polarimetric L-band acquisitions. The characteristics of the ESAR and LiDAR data sets are shown in Table 1.

Interferometric processing and DSM generation followed established procedures (e.g. Bamler and Hartl, 1998) using the Gamma Interferometric SAR Processor. Each of the three polarimetric L-band data sets $(\mathrm{HH}, \mathrm{HV}$ and $\mathrm{VV}$ polarization, where HV stands for horizontal transmit and vertical receive polarization) and the $\mathrm{X}(\mathrm{VV})$ image pair were co-registered and four interferograms were then generated: $\mathrm{X}(\mathrm{VV}), \mathrm{L}(\mathrm{HH}), \mathrm{L}(\mathrm{HV})$ and $\mathrm{L}(\mathrm{VV})$. Scattering phase centre height was estimated from the interferograms following eq. 3 by Madsen et al. (1993).

$$
h=H-r \cos \theta
$$

where $h$ is the height of the scattering phase centre $(\mathrm{m}), H$ is the altitude of the sensor $(\mathrm{m}), r$ is the range distance to the sensor $(\mathrm{m})$ and $\theta$ is the incidence angle.

Coherence images for each interferogram were derived using an adaptive spatial filter with window sizes ranging from $3 \times 3$ in high coherence areas to $9 \times 9$ in low coherence areas. Finally, the interferograms were unwrapped and the phase information was calibrated into absolute height estimates using a set of 20 ground control points of known topographic height derived from the LiDAR data set over unforested areas (Section 3.2). Quality control was carried out by examining the accuracy of each DSM over areas of bare ground (Section 4.1).

In forests three basic scattering mechanisms can be distinguished: volume scattering from the crowns and understorey / ground vegetation volumes, double-bounce scattering from trunk-ground and branchtrunk interactions and surface scattering from the rough soil surface. Depending on the wavelength, polarization and target properties the proportions by these three mechanisms can vary. The elevation values derived from InSAR DSM's correspond to scattering phase centre heights, i.e. the vertical location in the canopy from which the majority of the backscattered radiation comes. For dense forests and short wavelengths the scattering phase centre can be close to the canopy top, while for sparse forests with gaps and longer wavelengths they can be close to the forest floor. This needs to be borne in mind when interpreting interferometric heights.

\subsection{LiDAR Data}

A LiDAR data set was acquired over the Thetford area using the Airborne Laser Terrain Mapper (Optech ALTM 1210) instrument operated by the UK Environment Agency within 1 month of the ESAR flight. Laser pulses had a wavelength of $1.047 \mathrm{~mm}$ (near infrared). The footprint size of the laser pulse was between 0.2 to $0.3 \mathrm{~m}$ with approximately one data point recorded every $2.3 \mathrm{~m}^{2}$. The first and last significant LiDAR returns were recorded, although this research only considered the first return in the DSM creation ${ }^{1}$. The sensor was operated over a small look angle $\left( \pm 10^{0}\right)$ with a swath width of approximately $500 \mathrm{~m}$. These data were interpolated (by Kriging) to produce a DSM with a posting of $1 \mathrm{~m}$.

\subsection{Ordnance Survey Digital Terrain Model}

A critical source of information for estimating stand top height or mean height is a digital terrain model (DTM) that describes the terrain surface under the forest canopy. The availability of such information is often the limiting factor in obtaining surface feature heights. In this instance, terrain information was provided by the UK Ordnance Survey (OS) 'Land-Form PANORAMA' product with a pixel spacing of $50 \mathrm{~m}$ and a reported vertical accuracy of around $\pm 5 \mathrm{~m}$ (Ordnance Survey, 2000).

\footnotetext{
${ }^{1}$ The last return is of use in determining the depth of penetration of the LiDAR beam. In instances where the side of a sparse canopy is imaged, the ground height may be calculated using this value.
} 


\section{Results}

The main results are reported in three sections. Initially, the accuracy of the derived InSAR and LiDAR DSM's is assessed over bare areas of ground where interpretation of the remote sensing data is not complicated by the forest structure. The estimation of stand top height from each DSM is then assessed over Corsican Pine stands throughout the main forest block at Thetford and observations on the mechanisms affecting the remote sensing data are made. Mean stand height is also estimated from X-band InSAR. Finally, error propagation from noise in the DTM used in the top height and mean height estimations is briefly discussed.

\subsection{Deriving Height over Bare Ground}

The accuracy of InSAR scattering phase centre height measurements over forest areas tends to vary as the coherent signal may be degraded by temporal, geometric and volume decorrelation mechanisms (Zebker and Villasenor, 1992). In contrast, the quality of the LiDAR top of canopy height measurements remains high, although some penetration into the canopy does occur (Gaveau and Hill, 2003), even over mature forest stands - an area where InSAR coherence is often low and height measurements are often less accurate. If the surface roughness of the ground leads to a high signal-to-noise-ratio, InSAR coherence is often higher over bare ground where the properties of the scatterers are more stable than in the forest canopy. Therefore, under certain acquisition conditions the accuracy of an InSAR DSM over bare ground can indicate the maximum achievable vertical accuracy from that dataset. These results are an important pre-cursor to the more complex analysis when deriving forest stand height.

Twenty-two plots within the main area at Thetford were identified as bare ground. That is, areas of open fields not used for agricultural or forestry purposes but probably containing short grass (e.g. meadows). The selection of each area was based upon size, shape and spatial location. Large, compact areas located at various places throughout the forest were selected to reduce the impact of mis-registration of the remotely-sensed data and to also provide variety of test sites over the full incidence angle range of the SAR imagery.

Figure 5 shows the mean $\mathrm{L}(\mathrm{HH}), \mathrm{L}(\mathrm{HV})$ and $\mathrm{X}(\mathrm{VV})$ scattering phase centre heights derived over each bare ground area as a function of the mean height derived from the LiDAR data, as well as a comparison of the OS DTM with the LiDAR DSM over bare ground. The statistics for these plots are shown in Table 2 and include the rmse, standard deviation of the error (SDE) and coefficient of determination $\left(\mathrm{R}^{2}\right)$. In addition to these calculations, the 'expected' accuracy of the InSAR scattering phase centre height measurements was also derived following Rodriguez and Martin (1992, eq. 3). Equation 4 shows the expected height error caused by phase decorrelation:

$$
\sigma_{h}=\frac{\lambda r \tan \theta}{4 \pi B_{h}} \sigma_{\Phi}
$$

where $\left(\sigma_{h}\right)=$ height error $(\mathrm{m}) ; B_{h}=$ horizontal baseline $(\mathrm{m}) ; \theta=$ incidence angle; $r=$ range distance to the sensor (m); $\lambda=$ wavelength $(\mathrm{m}) ; \sigma_{\Phi}=$ phase noise over the local area.

Equation 4 may be used to predict the error in the InSAR scattering phase centre height estimates $\left(\sigma_{h}\right)$. The rmse and SDE shown in Table 2 indicate that the X-band system is more accurate at measuring the bare ground surface height that the L-band system. This is because coherence is higher reducing $\sigma_{\varphi}$, and $\lambda$ is smaller in the shorter wavelength X-band case resulting in a smaller height error in Equation 4 (Massonet and Rabaute, 1993). One main reason for the higher coherence at X-band is that it was acquired in single-pass while L-band was repeat-pass. Even for grassy vegetation the repeat-pass mode causes some temporal decorrelation. Also highlighted by Table 2 is the large variation in height error at the near-range of the SAR image (incidence angle $23^{\circ}$ ) compared to the far-range (incidence angle $67^{\circ}$ ). Height measurements in the near-range will be more accurate since the path length from the sensor to the ground is shorter when compared to the far-range of the image. This is a particular problem for airborne 
SAR instruments since the low flying height generally results in a large incidence angle range. These results already suggest that (i) relatively accurate estimates of stand height may be possible using the Xband scattering phase centre heights and (ii) errors will be encountered when correlating the L-band scattering phase centre height data with canopy height.

The OS DTM was also compared to the LiDAR results over the bare areas of ground. Table 2 shows an rmse of $\pm 1.3 \mathrm{~m}$, significantly smaller than the $\pm 5 \mathrm{~m}$ accuracy suggested for the UK wide OS DTM. The SDE was also calculated at $1.2 \mathrm{~m}$ suggesting only a minor systematic offset when compared with the LiDAR DSM.

\subsection{Deriving Stand Top Height}

Five data sets describing the forest stand top height for all Corsican Pine stands within the ESAR swath coverage were derived from the X-band, L-band and LiDAR data sets (XVV, LHH, LHV, LVV and LiDAR). The maximum scattering phase centre height (or LiDAR height) in each DSM was calculated over cell areas of $50 \mathrm{~m} \times 50 \mathrm{~m}$ to coincide with the $50 \mathrm{~m}$ pixel spacing of the OS DTM. The maximum tree height was then found by subtracting the OS DTM. These values are expected to be related to the height of the tallest tree in each cell. The stand top height was then estimated by averaging all cells within a forest stand. All boundary pixels (i.e. any $50 \mathrm{~m}$ size pixel which intersected a stand boundary) were excluded from the calculation to avoid mixed pixels with open ground and forest contributions to the signal. This process was completed for each of the five DSM's.

The use of the OS DTM to provide the ground height is not optimal and introduces an error into the estimation of stand top height (here the rmse between the OS DTM and the LiDAR DSM over bare ground was $\pm 1.3 \mathrm{~m}$, see Table 2). Although this error will be present in all stand height calculations, in many instances this data set is the only information available to provide the underlying terrain height, without which the calculation of stand height would not be possible except from interpolating an underlying terrain model from ground hits. In addition to this possible error source, a further two mechanisms should be considered when examining the InSAR and LiDAR results:

(i) Penetration of the SAR or LiDAR signal into the canopy

As the radar wavelength increases so does the penetration of the wave into the forest canopy. As a general rule, the main scattering elements tend to be of comparable size to the wavelength of the radiation. Therefore, $\mathrm{X}$-band radiation tends to be scattered by leaves and twigs at the top of the canopy, whereas L-band radiation tends to penetrate further into the canopy and is scattered by the main branches and tree trunks (Le Toan et al., 1992). Consequently, the scattering phase centre of the ESAR L-band measurements may not be found at the top of the forest canopy and estimates of stand height may appear to be lower than expected (Sarabandi and Lin, 2000). Even the shorter wavelength X-band scattering phase centre may underestimate the tree height over areas of sparse canopy coverage. In the case of LiDAR, Gaveau and Hill (2003) reported significant penetration of the LiDAR signal into a broadleaf natural forest canopy of up to $1.27 \mathrm{~m}$.

(ii) Gaps in the forest canopy

Top height was defined above as the average height of a number of 'top height trees' in a stand, where a 'top height tree' is the largest breast height diameter in a 0.01 ha sample plot. However, this does not compare directly with the estimates made by the LiDAR or SAR sensors, which respond to canopy height but not diameter at breast height. For example, the InSAR height calculation for each resolution cell may include contributions from scatterers from the ground, tree trunks and side of the crowns, particularly in areas where the forest stand is not fully stocked. As a result, when deriving the stand top height, gaps in the forest stand may contribute significantly to the overall measurement.

\subsubsection{ESAR results}

Figure 6 shows top height estimates derived from the L(HH), L(HV) and X(VV) datasets over all Corsican Pine stands plotted as a function of the modelled top height (derived from the yield class 
functions). The $\mathrm{L}(\mathrm{VV})$ results are not shown but are similar to the $\mathrm{L}(\mathrm{HH})$ plot. rmse and $\mathrm{R}^{2}$ of the top height estimates are given for L-band split by incidence angle bins in Table 3.

The L-band top height estimates derived from scattering phase centre heights show only a weak linear correlation with the yield class top height in all three polarizations (Figure 6a-b). In each case, large errors are observed over the entire age range of stands. A partial reason for such large errors is due to a decrease in coherence over the forest area (which ranged between 0.7 and 0.9). Temporal decorrelation effects, arising from changes in scene properties between the two image acquisitions, are a likely cause of the lower coherence (Zebker and Villasenor, 1992). The expected height error for the L-band estimates was calculated from eq. 4 for four incidence angle ranges and coherence values of 0.7 and 0.9 (Table 3). Table 3 shows that the expected height error at L-band increases from $0.5 \mathrm{~m}$ to $1.7 \mathrm{~m}$ in the near range and from $2.9 \mathrm{~m}$ to $9.5 \mathrm{~m}$ in the far range if coherence decreases from 0.9 to 0.7 .

The large incidence angle range, inherent to side looking airborne sensors, resulted in a large range of height errors across the swath. As a result, estimates of stand top height from L-band in the near-range with low incidence angles were more accurate than in the far-range with high incidence angles (Table 3). However, some near-range stands showed significant discrepancies from the predicted top height. Large underestimations in the stand top height estimates from L-band were observed (Figure 6a-b) even though the rmse was low (Table 3). Penetration of the L-band radiation through the canopy combined with the presence of gaps in the older stands may account for this (Sarabandi and Lin, 2000).

Estimates of stand top height derived from the ESAR X-band scattering phase centre heights were closer to the expected stand top height (Figure 6c). There is also a large incidence angle variation across the swath at X-band, but the shorter wavelength and higher coherence of the single-pass dataset resulted in the expected height error (eq. 4) varying from $0.2 \mathrm{~m}$ in the near-range to $1.9 \mathrm{~m}$ in the far-range of the $\mathrm{X}$-band image. However, the observed rmse $( \pm 2.9 \mathrm{~m}$ and $\pm 4.1 \mathrm{~m}$ respectively, $\mathrm{R} 2=0.77)$ was higher than the expected error. Figure $6 \mathrm{c}$ shows an underestimation in top height estimates from X-band for all stands taller than $15 \mathrm{~m}$ (i.e. older than approximately 25 years). This change in the relationship tends to coincide with the first thinning rotation of stands at Thetford forests and suggests a link with forest management practices for all maturing stands.

To examine the effect of measuring stand top height at different incidence angles, 4 x 10 year age groups were defined and the ESAR X(VV) top height from scattering phase centres was plotted as a function of incidence angle, as shown in Figure 6d. A relatively large age range was required to give a large enough number of stands within each group. Height variation within each group due to this age range is around $5 \mathrm{~m}$. Age ranges over 40 years were not included due to the low number of older stands within the test site. A general trend of increasing height estimates as the incidence angle increases is observed over each of the four age groups (Figure 6d). However, the main reason for this increase cannot be wholly associated with the canopy gap fraction since the trees are densely planted for both groups two and three (i.e. stand ages between 10 to 30 years). A suggestion for the observed response is found by considering canopy roughness as observed by the SAR. The Corsican Pine crowns are generally cone shaped with the diameter of the crown ranging from $1 \mathrm{~m}$ for young stands to $8 \mathrm{~m}$ for the oldest stands. Therefore, the profile of the canopy viewed by the SAR sensor at high incidence angles includes a greater amount of the side of tree crowns than at low incidence angles, i.e. the canopy looks rougher at high incidence angles. Consequently, the height estimated in each resolution cell at the near-side of the image may be lower when compared with estimates made over stands at the far-side, even if there are no gaps between tree crowns.

Sarabandi and Lin (2000) also predict this response by modelling the scattering phase centre of a C-and L-band system as a function of incidence angle. A strong increase in the estimated InSAR height with incidence angle was predicted over a moderately stocked Jack Pine stand ${ }^{2}$. Although, a more densely stocked stand of Red Maple ${ }^{3}$ did not show any change in the estimated InSAR height at various incidence

\footnotetext{
${ }^{2}$ Dry biomass density of 53t/ha, tree density of 1142 trees/ha. Similar to a 20 year old pine stand at Thetford forest.

${ }^{3}$ Dry biomass density of $140 \mathrm{t} / \mathrm{ha}$, tree density of 1700 trees/ha. Similar to a 50 year old stand at Thetford forest.
} 
angles. The shape of tree crowns was the given reason for the two different responses (also discussed in Balzter et al., 2001).

An empirical model may be derived to compensate for this effect. Table 4 shows the gradients and constants from the linear equations of the four fitted lines in Figure $6 \mathrm{~d}$. The mean gradient of these linear functions was used to calculate an adjusted stand top height using Equation 5:

$$
H_{\text {Model }}=H_{\text {InSAR }}-M \theta
$$

where $\mathrm{H}_{\text {model }}=$ Adjusted top height $(\mathrm{m}), \mathrm{H}_{\text {InSAR }}=\mathrm{InSAR}$ derived top height, $\mathrm{M}=1.71$ (i.e. the mean gradient in Table 4) and $\theta=$ incidence angle to the centre of the forest stand. Figure 7 a shows the results after applying this model to the X-band data. The rmse of the top height estimates decreased from $\pm 4.1 \mathrm{~m}$ to $\pm 2.9 \mathrm{~m}$ after applying this compensation model (the SDE decreased from $2.8 \mathrm{~m}$ to $2.1 \mathrm{~m}$ and $\mathrm{R}^{2}$ increased from 0.77 to 0.80 ). A factor not accounted for by this model is that as stand age increases so does the surface roughness since the crown dimensions (width and height) also increase with stand age. Thus, the height underestimation for older stands, as a function of incidence angle, will in fact be greater than for younger stands. In addition, the effect of gaps in the forest canopy are also not accounted for and the abrupt underestimation in stand top height for stands taller than $15 \mathrm{~m}$, (older than 25 years) is still observed. This is a limitation when deriving stand top height from the scattering phase centre heights in the way described here. To obtain more accurate results, the forest structure must be accounted for in the calculation (e.g. gaps and crown shape) as a function of multiple SAR system parameters (e.g. wavelength and incidence angle).

\subsubsection{LiDAR Results}

One might expect to see an increase in the accuracy of the top height estimates when using the LiDAR data. Various other authors have recorded highly accurate results when deriving tree heights (e.g. Naesset, 2004). In addition, penetration of the LiDAR beam into the canopy has a relatively small impact on the results compared to the errors observed in the X-band data and so does the small incidence angle range of the LiDAR swath (Holmgren et al., 2003b). Figure 7b shows the LiDAR derived top height estimate compared to the Forestry Commission top height. The accuracy of the top height estimate from LiDAR is higher than from $\mathrm{X}$-band ( $\mathrm{SDE}=1.5 \mathrm{~m}$ for LiDAR compared to $\mathrm{SDE}=2.9 \mathrm{~m}$ for $\mathrm{X}-\mathrm{VV}$ ). The overall rmse is $\pm 2.0 \mathrm{~m}$ from LiDAR compared to $\pm 4.1 \mathrm{~m}$ from X-band InSAR (no incidence angle correction).

There is no abrupt change in the predicted top height for the mature forest stands. A possible reason for this concerns the small size of the LiDAR footprint. The area imaged by the LiDAR sensor is only around $0.3 \mathrm{~m}$ in diameter with measurements made every $2-3 \mathrm{~m}$. The data may be thought of as taking point height measurements over the entire forest stand. As a result, only a small minority of pixels will contain a mixture of contributions from the ground, sides of tree crowns and the canopy top. The majority of measurements will be either canopy top, ground hits or tree crown side returns. This aids the estimate of top height since only the maximum height return over a $50 \mathrm{~m}$ x $50 \mathrm{~m}$ cell is used in the calculation. This maximum value is more likely to be a measurement made entirely over the canopy top than in the ESAR case which derives the height over a much larger resolution cell $(3.98 \mathrm{~m}$ x $0.72 \mathrm{~m})$.

\subsection{Height histogram comparison between LiDAR and X-band SAR}

An explanation for the abrupt change in the linear relationship of the X(VV) top height estimates derived from the scattering phase centres observed in Figure $6 \mathrm{c}$ is apparent after examining a set of LiDAR and X-band DSM height histograms over a range of stand ages.

Figure 8a-c show three LiDAR histograms over stands aged 16, 34 and 70 years old. A Gaussian distribution is expected based upon height measurements made during the ThetfordGC. This is generally observed in the younger stands, although the histogram becomes skewed and tends towards a flatter distribution in older stands. This may be explained by gaps in the forest canopy large enough to influence the LiDAR signal. Line thinning strategies are employed at Thetford on a five year rotation (Edwards, 
1981). The number of trees in each stand is significantly reduced to encourage growth of the remaining stock. As a result, the canopy coverage decreases after the first thinning phase, i.e. for stands between 19 to 24 years old depending on the yield class of the stand. This typically results in a noticeable separation between the tree crowns after the second thinning rotation when stands are aged between 24 and 29 years. Therefore, the probability of the LiDAR pulse (or, in the ESAR case, the electromagnetic wave) interacting with the side of the crowns, trunks or ground will increase with stand age. The height histograms from the ESAR X-band dataset (Figure 8d-f) show an increasing spread of height values within the stand for increasing stand age, similar to the LiDAR histograms (Figure 8a-c). However, the range of height values for older stands from SAR is narrower than that from LiDAR. The distribution of the X-band height values tends to deviate from a Gaussian towards a more skewed distribution for increasing stand age. The degree of skewness is smaller than in the LiDAR results. This relates to the relatively small size of the LiDAR footprint in comparison to the larger ESAR resolution cell.

Further evidence supports the suggestion that gaps in the forest canopy increase with stand age are found by examining the ThetfordGC field measurements. Stands younger than 15 years and older than 30 years tend to have a total canopy coverage of less than $100 \%$. That is, the canopy closure is not sufficient to completely shadow the ground from a nadir viewing position. Stands between 15 and 30 years old all show dense canopy coverage with a large amount of overlap occurring between tree crowns. In addition, measurements of the tree spacing suggests the majority of the crown overlap occurs between trees planted in the same row, i.e. the spacing of trees within the same row is less than the average size of the tree crown, and that the distance between rows of trees is often larger than the crown size. Therefore, the orientation of tree rows with respect to the SAR sensor may also play a role when assessing the effect of gaps in the canopy on the SAR measurements. This needs further investigation.

\subsection{Deriving Mean Stand Height from X-band InSAR}

Results from the previous section indicate the problems in deriving stand top height when using remotely sensed data with resolution cells larger than individual tree crowns. The roughness of a continuous canopy and gaps over a sparse canopy contribute a significant component to the overall height measurement made by the InSAR system. A possible way to reduce these effects on the InSAR height measurement is to estimate the mean stand height rather than the top height from the scattering phase centre height. As discussed in Section 2.2, the yield class models may be used to predict the mean height of a stand which will inherently include the stocking density and canopy coverage components. Because of these factors as well as the wave penetration into the canopy, the interpretation of the InSAR scattering phase centre height measurement as an estimate of mean canopy height is simplified.

Mean stand height was estimated from the ESAR X(VV) interferogram as the average height of the scattering phase centre over the forest stand. In contrast to the top height estimation described previously, instead of calculating the maximum scattering phase centre height in each $50 \mathrm{~m} \times 50 \mathrm{~m}$ cell, the mean scattering phase centre height is now calculated. All boundary pixels were discarded to avoid mixed bare soil/forest pixels contaminating the results.

Figure 9 shows the $\mathrm{X}(\mathrm{VV})$ derived mean stand height estimate plotted as a function of the predicted mean stand height from the yield class models. For the mean stand height estimation from X-band accuracy figures are better $\left(\mathrm{SDE}=1.5 \mathrm{~m}\right.$, rmse $= \pm 2.5 \mathrm{~m}$, and $\mathrm{R}^{2}=0.87$ ) than for the top height estimation from X-band $\left(\mathrm{SDE}=2.9 \mathrm{~m}\right.$, rmse $\left.= \pm 4.1 \mathrm{~m}, \mathrm{R}^{2}=0.77\right)$. Most noticeably, the abrupt underestimation in top height observed for stands taller than $15 \mathrm{~m}$ is no longer present (compare Figure 7a and Figure 9). The yield class model estimate of mean stand height implicitly accounts for the reduction in tree density and subsequent increase in gaps between the crowns.

\subsection{Error model}

The accuracy of the OS DTM plays a role in causing the spread of points in the scatterplots of remotely sensed top/mean height estimates vs. the control height values from the Forestry Commission GIS. The exact accuracy value of the OS DTM over the site is not known, but an rmse of $\pm 1.3 \mathrm{~m}$ was found 
between the OS DTM and the LiDAR DSM over bare ground, and the Ordnance Survey itself states an accuracy of $\pm 5 \mathrm{~m}$ for this data product generally. In reality each point location in the test site has a true unknown elevation above mean sea level, and a value in the OS DTM that is used as an estimate of the true value. The differences between these values constitute the error of the OS DTM. A simple error model was used to quantify how the variability of the unknown error in the OS DTM would combine with the error in the remotely sensed datasets and propagate to the final canopy height estimate. The simplest error model can be defined by drawing random values from a normal distribution with zero mean and the estimated rmse as standard deviation, on the assumption that the rmse is an unbiased estimate of the standard deviation. This defines a white noise process. Eq. 6 illustrates that the estimated canopy height $\hat{h}$ is derived from a linear combination of the remotely sensed height $h_{R S}$, which consists of terrain plus canopy height, and the OS DTM height $h_{O S}$ as an estimate of the underlying terrain.

$$
\hat{h}=h_{R S}-h_{O S}
$$

Both terms include error components $e_{R S}$ and $e_{O S}$, so that the unknown true canopy height $h$ can be modelled as:

$$
h=h_{R S}-e_{R S}-e_{O S}-
$$

Assuming both error terms are independent white noise processes, the variance of the sum or difference of $h_{R S}$ and $h_{O S}$ is the sum of their individual variances, so that the error of the estimated canopy height $e_{\hat{h}}$ can be estimated from the squared rmse values:

$$
e_{\hat{h}}=\sqrt{e_{R S}^{2}+e_{O S}^{2}}
$$

Figure 10a illustrates how for a constant $e_{R S}=3.5 \mathrm{~m}$ an increasing $e_{O S}$ leads to an increasing $e_{\hat{h}}$. The growth rate of canopy height error $e_{\hat{h}}$ increases more slowly for increasing OS DTM errors (right), and stabilizes at some upper saturation limit because of the diminishing effect of the (constant) error term of the remotely sensed height in comparison to the OS DTM error (Figure 10b).

\section{Discussion}

This study presents a comparison of estimating stand top height and mean stand height from scattering phase centre heights derived from a single pass X-band SAR interferogram, a set of repeat-pass L-band interferograms at different polarisations and from LiDAR, utilising the OS DTM as a model of the terrain surface under the forest. As expected, results from the L-band interferometric scattering phase centres showed larger deviations from forest stand top height than the X-band estimates because of wavelengthspecific differences in radiation penetration through the canopy and temporal decorrelation effects between the repeat-pass L-band images. It should be noted that better results may be obtained by introducing a model to predict the coherent extinction of the radiation through the canopy at various incidence angles, taking into account specific physical properties of the forest (e.g. Papathanassiou and Cloude 2001). The empirical incidence angle correction presented here works but is stand specific. A physically based incidence angle correction would provide a more generic methodology. It would have to take into account the forest canopy structure and radar illumination geometry of tree crowns as a function of viewing geometry.

The $\mathrm{X}(\mathrm{VV})$ signal penetrates less deeply into the canopy than the L-band radiation. Also, in single-pass mode coherence over the forest stands remained extremely high (0.99 to 0.90) resulting in an expected height error between 0.3 and $1.9 \mathrm{~m}$ at the near and far-side of the image respectively. These factors allowed a simpler interpretation of the X-band results compared to the L-band data sets. However, accuracy of the $\mathrm{X}(\mathrm{VV})$ top height estimates tended to be dominated by two factors related to the characteristics of Thetford forest, namely gaps in the forest canopy and the canopy roughness, relating to crown shape and tree spacing. Both factors were further complicated by the large incidence angle range and resolution cell size of the InSAR sensors. Consequently, the empirical approach taken only allowed 
top height to be estimated from the X(VV) data set with an rmse of $\pm 4.1 \mathrm{~m}$ which was reduced to $\pm 2.9 \mathrm{~m}$ when accounting for the incidence angle range of the ESAR sensor.

A critical difference between the InSAR and LIDAR data sets is that the LiDAR footprint is far smaller than the ESAR resolution cell (covering an area of approximately $0.3 \mathrm{~m}^{2}$ and $2.93 \mathrm{~m}^{2}$ respectively). As a result, the LiDAR height estimates over a $50 \mathrm{~m} \times 50 \mathrm{~m}$ area will be more likely to contain heights from measurements made over individual tree crowns. The X(VV) scattering phase centre height estimates may contain a mixture of tree crowns, side of tree crowns and even ground components. As a result, the LiDAR data set is better suited to derive stand top height than the X(VV) data set. An rmse of $\pm 2.0 \mathrm{~m}$ was recorded when using the LiDAR data to estimate top height. Consequently, a second metric for stand height was introduced to utilize the full potential of the X(VV) data set. The accuracy of the OS DTM that was used for terrain height will impact on the stated accuracy figures for the remotely sensed vegetation height values. If a better way of deriving terrain height was found the overall error figures could be further reduced.

At Thetford forest, available field measurements and yield class models allowed an empirical model for the mean stand height to be derived based upon the top height and the stocking density of the stand. It has to be noted that general yield class models were developed for managed forests, single-species plantations and only for commercially valuable tree species. Under more natural unmanaged conditions like mixedspecies forest communities or naturally regenerating forests, the allometric relationships are questionable. In this study we found better accuracy of the X(VV) scattering phase centre based height estimates were observed for mean stand height rather than top height. Importantly, the underestimation in top height estimates for mature stands, caused by the thinning regime at Thetford, is not present in the mean stand height estimates. Critically, a strong linear relationship is observed over the entire age range of stands at Thetford. Retrievals of mean stand height were reported with an rmse of $\pm 2.5 \mathrm{~m}$. The results suggest Xband single-pass InSAR can under similar circumstances like at Thetford forest give extremely high accuracies of mean canopy height estimates from the scattering phase centres similar to LiDAR, suitable for carbon inventories. With some adjustment to the yield class models available, mean stand height estimates were made from SAR over the entire forest with an accuracy similar to the LiDAR results (rmse of $\pm 2.5 \mathrm{~m}$ in the ESAR X-band case compared with $\pm 2.0 \mathrm{~m}$ in the LiDAR case). A limitation of the method is that the test site is characterised by relatively flat terrain and homogeneous single-species evenaged plantations. Under hilly conditions the SAR data would be influenced by terrain distortions, layover and radar shadow in steep terrain, and potential effects on the interferometric phase noise. Equally, a heterogeneous multi-species forest with a variety of tree age would mean that the levels of accuracy we found in the Thetford forest study presented here would most probably not be attainable under those heterogeneous conditions.

\section{Acknowledgments}

This work was carried out by Laine Skinner during his PhD studies. The Thetford Ground Campaign (2000) was supported by the NERC and the British National Space Centre LINK project 'Carbon Offset Verification of Forest Ecosystems' No. R4/039. The authors would also like to thank the UK Environment Agency for supplying the raw LiDAR data. This work was supported by the UK Natural Environment Research Council. We thank the reviewers for their helpful comments that have substantially improved the paper.

\section{References}

Askne, J., Dammert, P.B.G., Ulander, L.M.H. and Smith, G., 1997, C-band repeat-pass interferometric SAR observations of the forest, IEEE Transactions on Geoscience and Remote Sensing 35, 25-35

Bamler, R. and Hartl, P., 1998, Synthetic Aperture Radar interferometry, Inverse Problems, 14, R1-R54 Baltsavias, E. P., 1999, Airborne laser scanning: existing systems and firms and other resources, ISPRS Journal of Photogrammetry and Remote Sensing 54, 164-198 
Balzter, H., Saich, P., Luckman, A., Skinner, L. and Grant, J., 2001, Forest stand structure from airborne polarimetric InSAR, In $3^{\text {rd }}$ International Symposium on Retrieval of Bio- and Geophysical Parameters from SAR data for Land Applications, $11^{\text {th }}-14^{\text {th }}$ Sept. 2000, Sheffield, UK

Cloude, S. R., and Corr, D., 2003, Tree height retrieval using single baseline polarimetric interferometry, Proceedings of POLInSAR 2003, Frascati, Italy, 1416 January 2003.

Dammert, P. B. G., and Wegmüller, U., 1999, JERS INSAR DEM quality assessment for a boreal test site, Proceedings of IGARSS'99, Hamburg, 28 June - 2 July 1999, 1930-1932.

Dammert, P.B.G., Ulander, L. and Askne, J., 1995, SAR interferometry for detecting forest stands and tree height, In Proc. of the European Symposium on Satellite Remote Sensing II, $25^{\text {th }}-29^{\text {th }}$ Sept., Paris, France, 384-390

Edwards, P.N., 1981, Yield models for forestry management, Booklet 48, Technical report, Forestry Commision, Thetford, UK

Floury, N., Le Toan, T., Souyris, J.-C., Singh, K., Stussi, N., Hsu, C. C., and Kong, J. A., 1996, Interferometry for forest studies, Proceedings of Fringe 96, Zürich, 30 Sept.- 2 Oct. 1996, 57-70

Gaveau, D.L.A. and Hill, R.A., 2003, Quantifying canopy height underestimation by laser pulse penetration in small-footprint airborne laser scanning data, Canadian Journal of Remote Sensing 29, 650657

Hoekman, D. and Varekamp, C., 2001, Observation of tropical rain forest trees by airborne highresolution interferometric radar, IEEE Transactions on Geoscience and Remote Sensing 39, 584-594

Holmgren, J., Nilsson, M. and Olsson, H., 2003a, Estimation of tree height and stem volume on plots using airborne laser scanning, Forest Science, 49, 419-428

Holmgren, J., Nilsson, M. and Olsson, H., 2003b, Simulating the effects of LIDAR scanning angle for estimation of mean tree height and canopy closure, Canadian Journal of Remote Sensing 29, 623-632

Hyyppä, J., and Engdahl, M., 2000, Verification of the capability of repeat-pass SAR interferometry to provide tree height information in boreal forest zone, Proceedings of IGARSS 2000, Honolulu, USA, 24-28 July 2000, 402-404

Keller M, Alencar A, Asner GP, Braswell B, Bustamante M, Davidson E, Feldpausch T, Fernandes E, Goulden M, Kabat P, Kruijt B, Luizao F, Miller S, Markewitz D, Nobre AD, Nobre CA, Priante N, da Rocha H, Dias PS, von Randow C, Vourlitis GL (2004) Ecological research in the large-scale biosphereatmosphere experiment in Amazonia: Early results, Ecological Applications 14, S3-S16

Kobayashi, Y., Sarabandi, K., Pierce, L. and Dobson, C., 2000, An evaluation of the JPL TOPSAR for extracting tree heights, IEEE Transactions on Geoscience and Remote Sensing 38, 2446-2454

Le Toan, T., Beaudoin, J.R. and Guyon, D., 1992, Relating forest biomass to SAR data, IEEE Transactions on Geoscience and Remote Sensing 30, 403-411

Madsen S.N., Zebker, H.A. and Martin, J., 1993, Topographic mapping using radar interferometry: Processing techniques, IEEE Transactions on Geoscience and Remote Sensing 31, 246-256

Massonet, G. and Rabaute, T., 1993, Radar Interferometry: Limits and potential, IEEE Transactions on Geoscience and Remote Sensing 31, 455-464

Mitchell, P.L., 1989, JPL SAR Campaign: Thetford Forest, August 1989. Second report on the collection of forestry ground data, Technical report, Botany School, Cambridge, UK

Naesset, E., 2004, Practical large-scale forest stand inventory using a small-footprint airborne scanning laser, Scandinavian Journal of Forest Research 19, 164-179

Nelson, R., Krabill, W. and Maclean, G., 1984, Determining forest canopy characteristics using airborne laser data, Remote Sensing of Environment 15, 201-212

Nepstad, D. C., Verissimo, A., Alencar, A., Nobre, C., Lima, E., Lefebvre, P., Schlesinger, P., Potter, C., Moutinho, P., Mendoza, E., Cochrane, M., and Brooks, V., 1999, Large-scale impoverishment of Amazonian forests by logging and fire, Nature, 398, 505-508.

Ordnance Survey, 2000, Land-form PANORAMA: User Guide v3.0, Technical report, Ordnance Survey, Southampton, UK 
Papathanassiou, K. P., Mette, T., and Hajnsek, I., 2003, Model based forest height estimation from single baseline Pol InSAR data: The Fichtelgebirge test case, Proceedings of POLInSAR 2003, Frascati, Italy, 14-16 January 2003

Papathanassiou, K.P. and Cloude, S.R., 2001, Single-Baseline polarimetric SAR interferometry, IEEE Transactions on Geoscience and Remote Sensing 39, 2352-2363

Ratcliffe, P. and Harris, S., 1996, Thetford Forest park symposium: a summary, In Proc. of Thetford Forest Park - The ecology of a pine forest, Forestry Commission, Thetford, UK, 169-174

Rodriguez, E. and J.M. Martin, 1992, Theory and design of interferometric synthetic aperture radars, IEE Proceedings, 139, 147-159

Santoro, M., Askne, J., and Dammert, P., 2003, Tree height estimation from multi temporal ERS SAR interferometric phase, Proceedings of Fringe'03, Frascati, Italy, 15 December 2003

Santoro, M., Askne, J., Smith, G., Dammert, P. and Fransson, J., 2000, Boreal forest monitoring with ERS coherence, Proc. ERS-ENVISAT Symposium, Gothenburg, Sweden, 16-20 October 2000, ESA SP461

Sarabandi, K. and Lin, Y., 2000, Simulation of interferometric SAR response for characterizing the scattering phase centre statistics of forest canopies, IEEE Transactions on Geoscience and Remote Sensing 38, 115-125

Skinner, L. and Luckman, A., 2000, Thetford forest ground data collection campaign in support of the SHAC SAR acquisition, June 2000, Technical report, Swansea University, UK

Skinner, L., Luckman, A., Balzter, H., 2002, Estimating forest stand height using SAR interferometry: A case study at Thetford forest using spaceborne and airborne interferometric systems, Proc. of ForestSAT: Operational tools in forestry using remote sensing techniques, $5^{\text {th }}-9^{\text {th }}$ August 2002, Edinburgh, UK

Tansey, K.J., Luckman, A., Skinner, L., Balzter, H., Strozzi, T., Wagner, W., 2004, Classification of global forest volume resources using ERS tandem coherence and JERS intensity data, International Journal of Remote Sensing 25, 751-768

Treuhaft, R. and Siqueira, P., 2000, Vertical structure of vegetated land surfaces from interferometric and polarimetric radar, Radio Science 35, 141-177

Zebker, H. and Villasenor, J., 1992, Decorrelation in interferometric radar echos, IEEE Transactions on Geoscience and Remote Sensing 30, 950-959

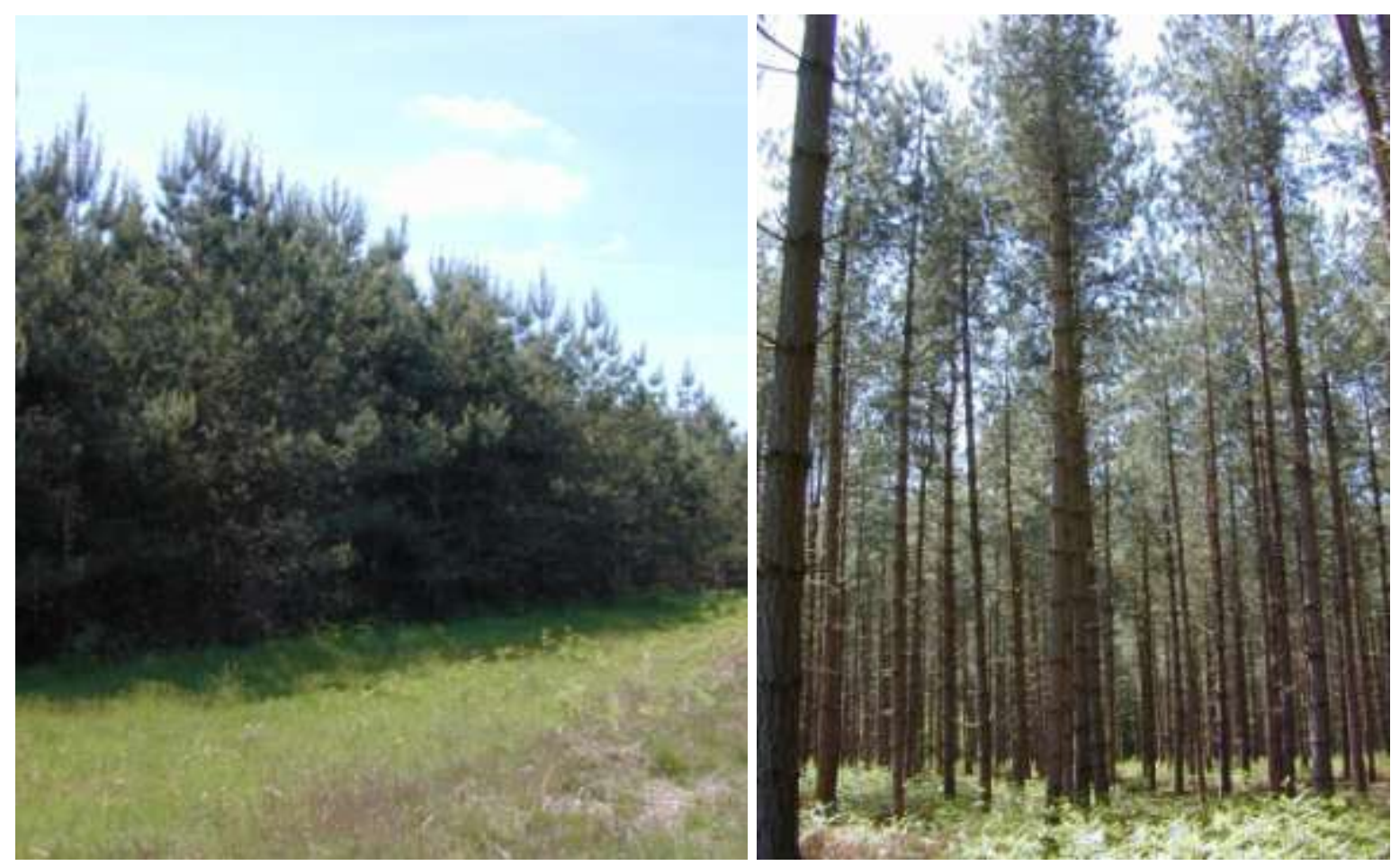


Figure 1: Photographs of a) a 16 year old Corsican Pine stand (canopy height $\sim 7 \mathrm{~m}$ ) and b) a 34 year old Corsican Pine stand (canopy height $\sim 20 \mathrm{~m}$ ). Photographs were kindly provided by Dr Paul Saich, London.

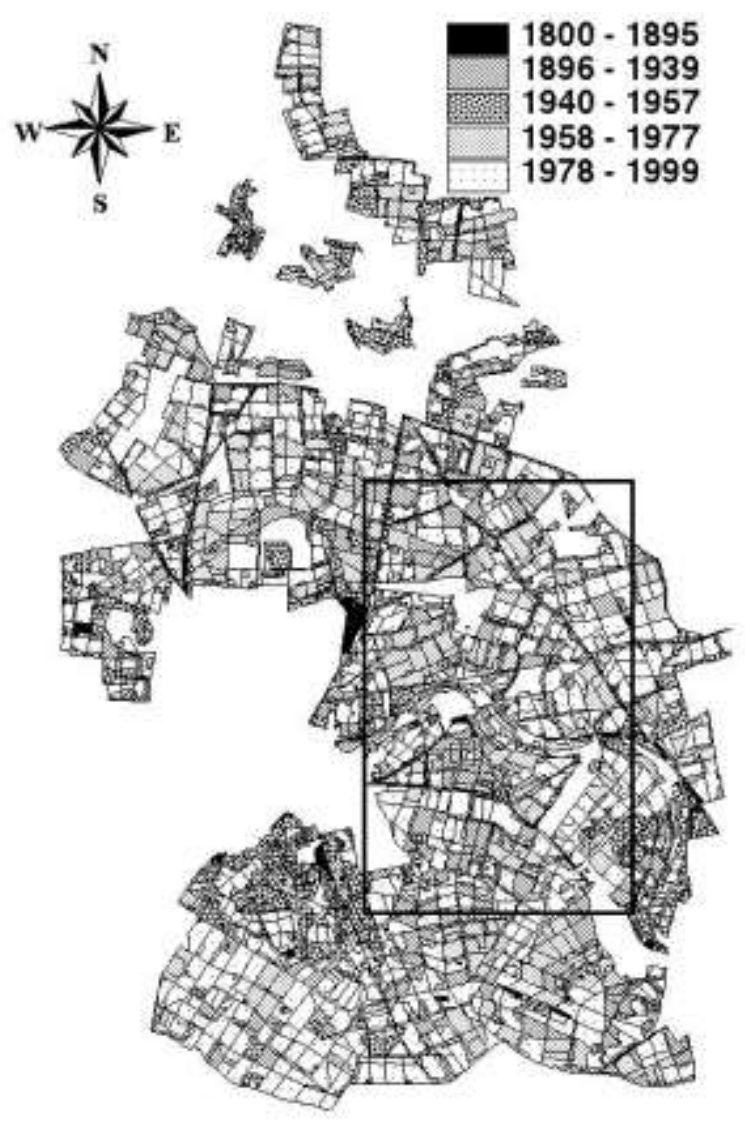

Figure 2: Forestry Commission GIS data layer for Thetford forest. The planting time period of each stand at Thetford is shown along with an outline of the area covered by the ESAR sensor. Multiple LiDAR overpasses were also acquired to cover the area flown by the single ESAR flight. 


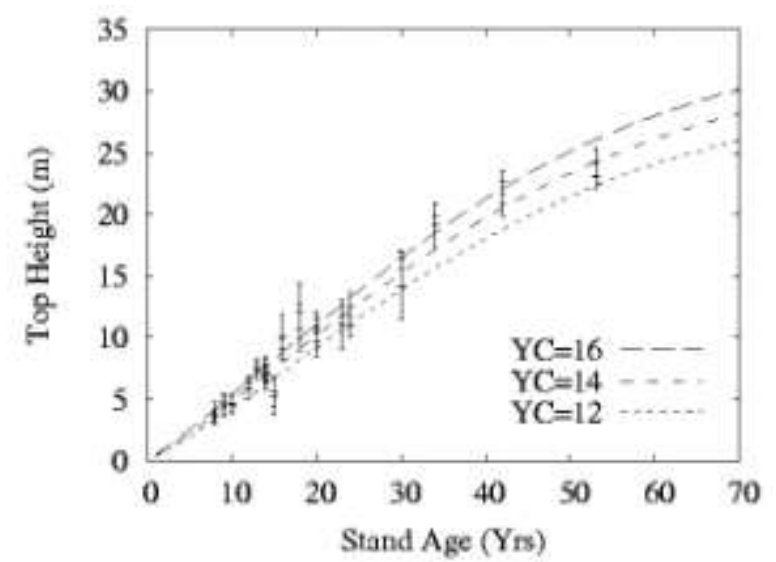

(a)

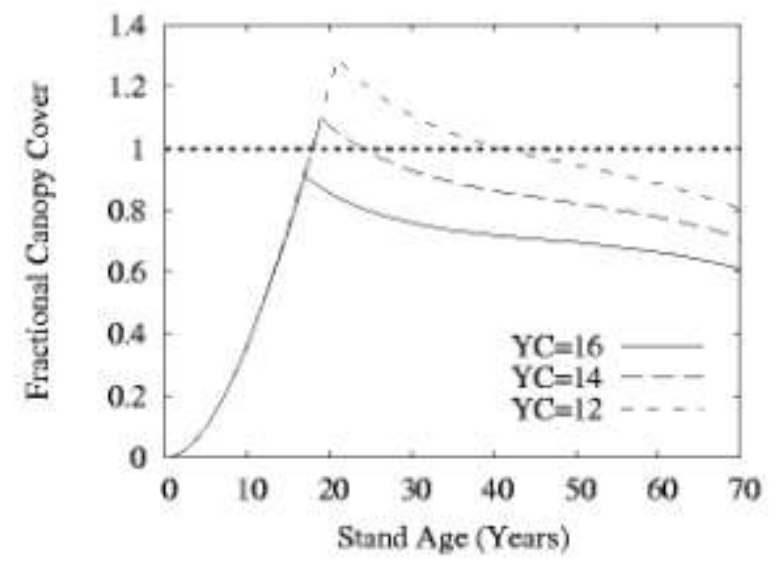

(b)

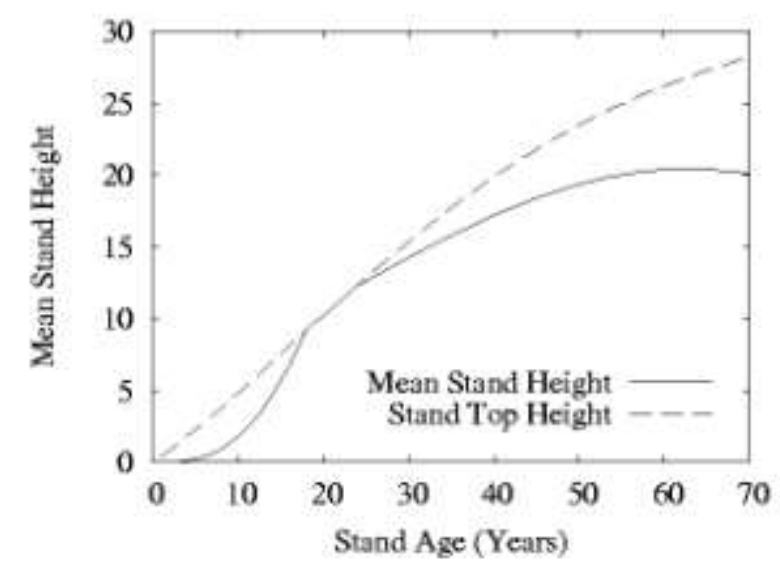

(c)

Figure 3: Model functions relating forest parameters to stand age and yield class: a) the yield class model predicting top height (field measurements are overlaid), b) fractional canopy coverage from a nadir position (derived from field measurements) and c) mean stand height for yield class 14, found by weighting the top height with the fractional canopy coverage. 


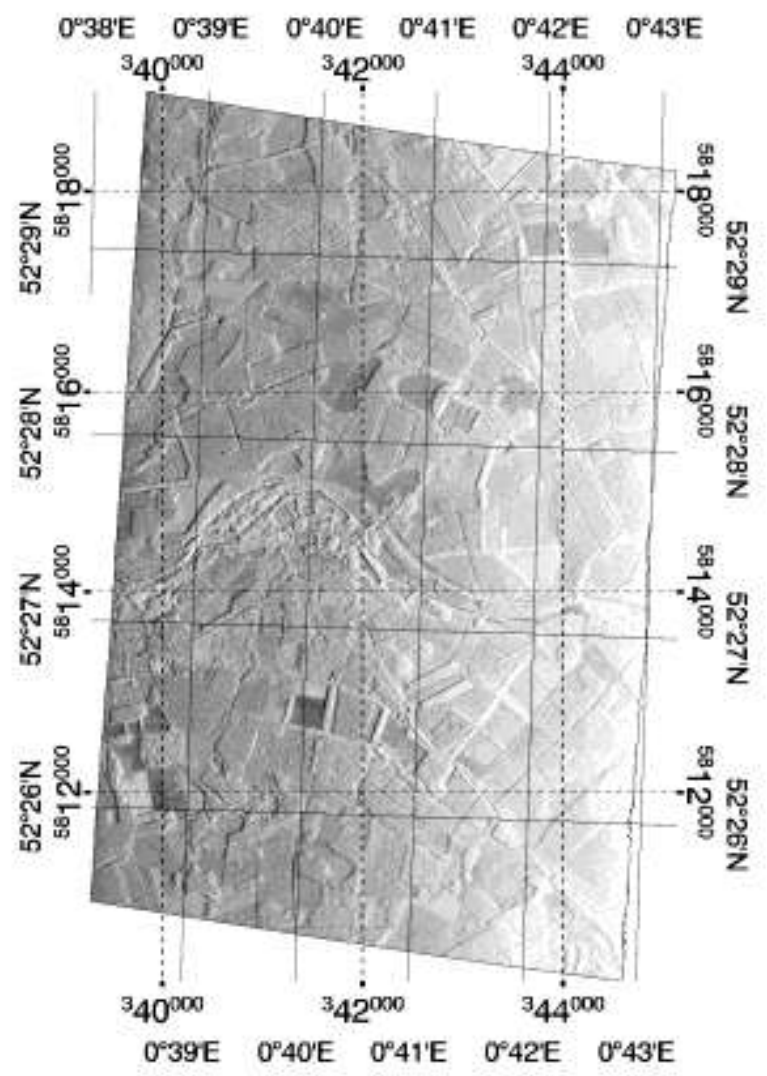

Figure 4: E-SAR X(VV) backscatter image of Thetford forest. 


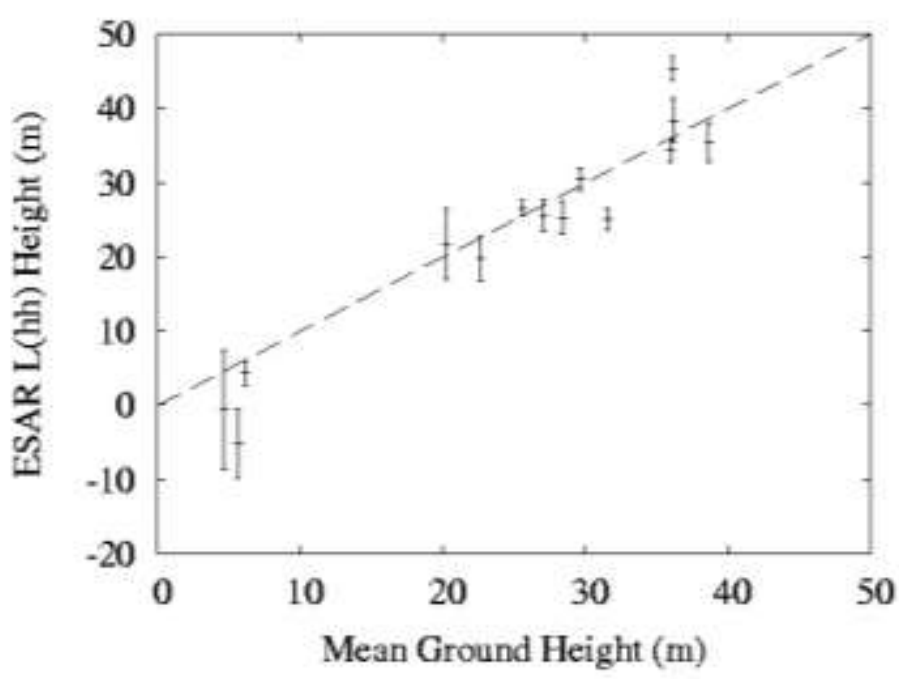

(a)

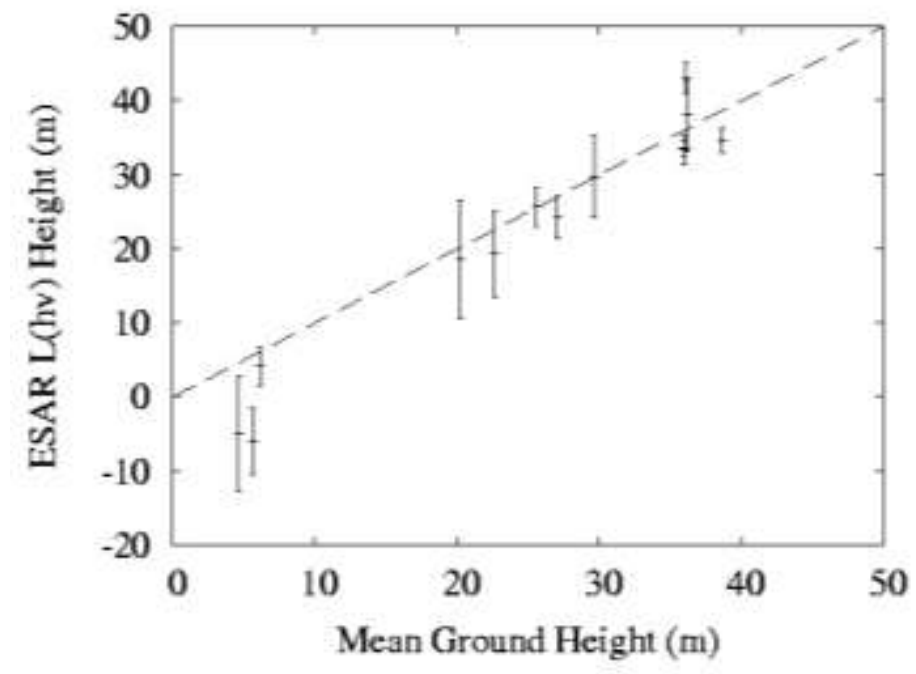

(b)

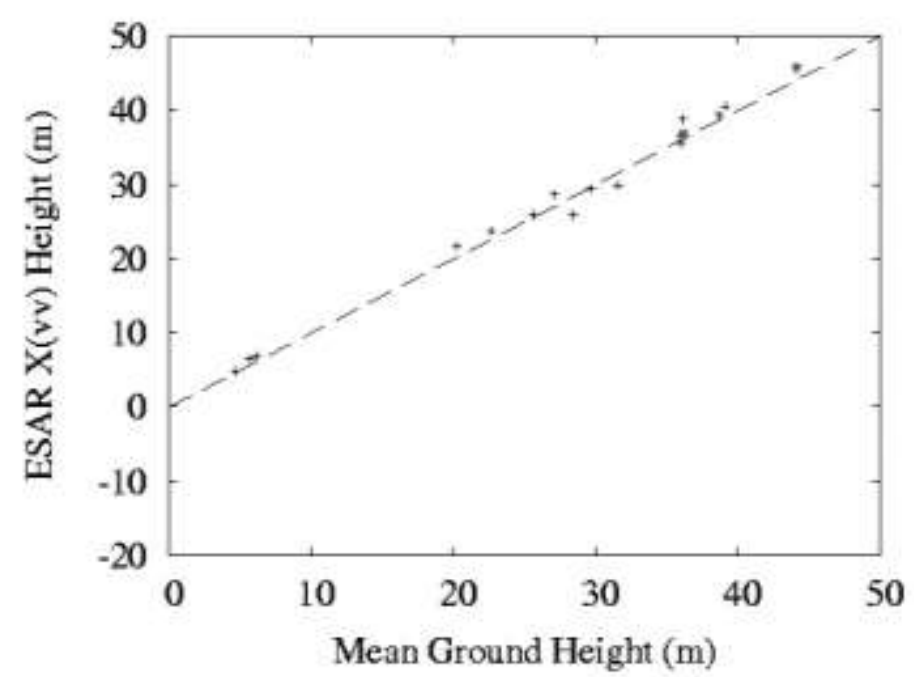

(c)

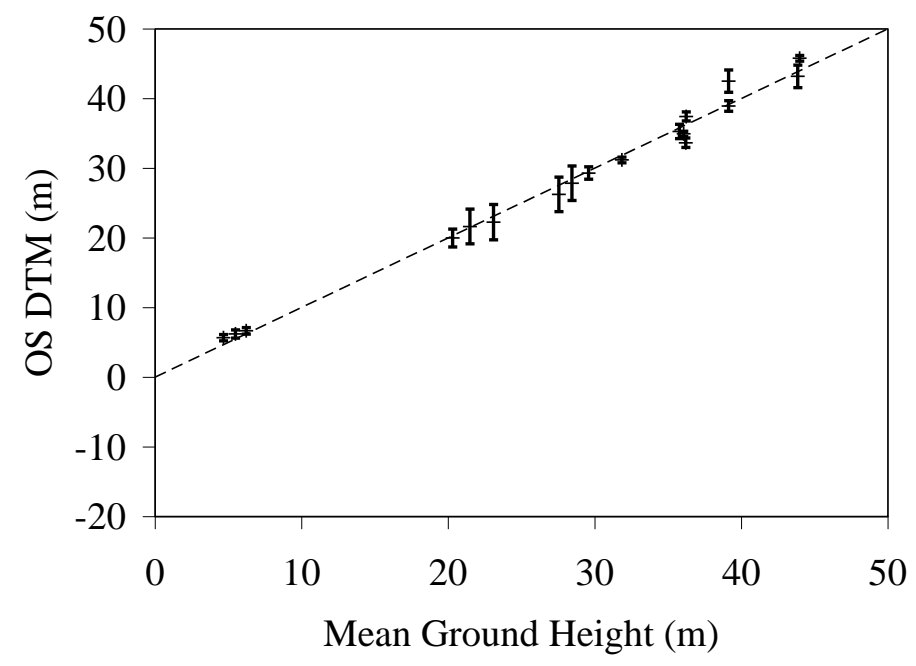

(d)

Figure 5: Mean ground height derived from, a) ESAR L(HH), b) L(HV), c) X(VV) scattering phase centre DSM's over bare ground, and d) the OS DTM over Thetford forest. The reference mean ground height on the $\mathrm{x}$ axis was derived from the LiDAR DSM over selected unforested stands. Error bars indicate the standard deviation. 


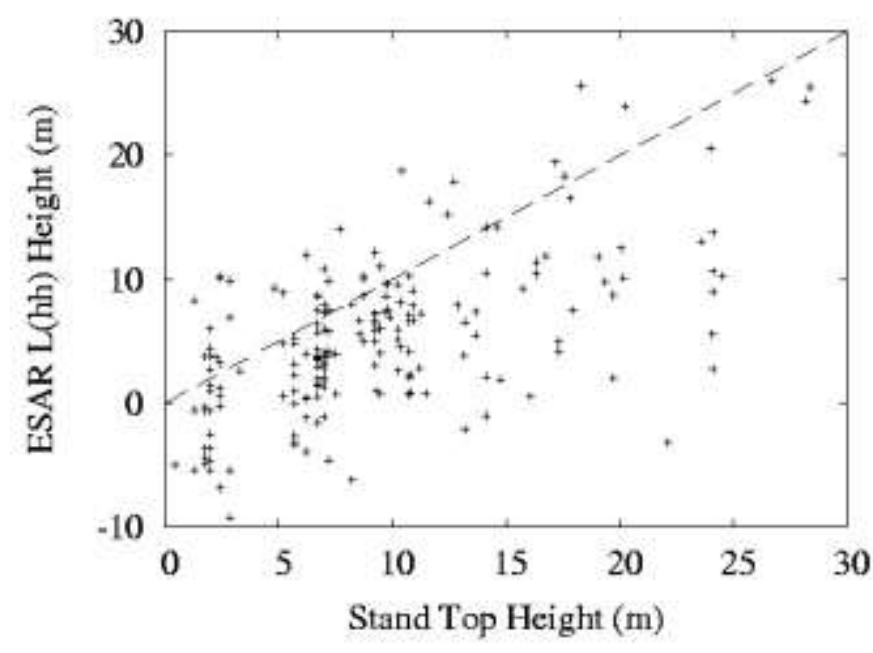

(a)

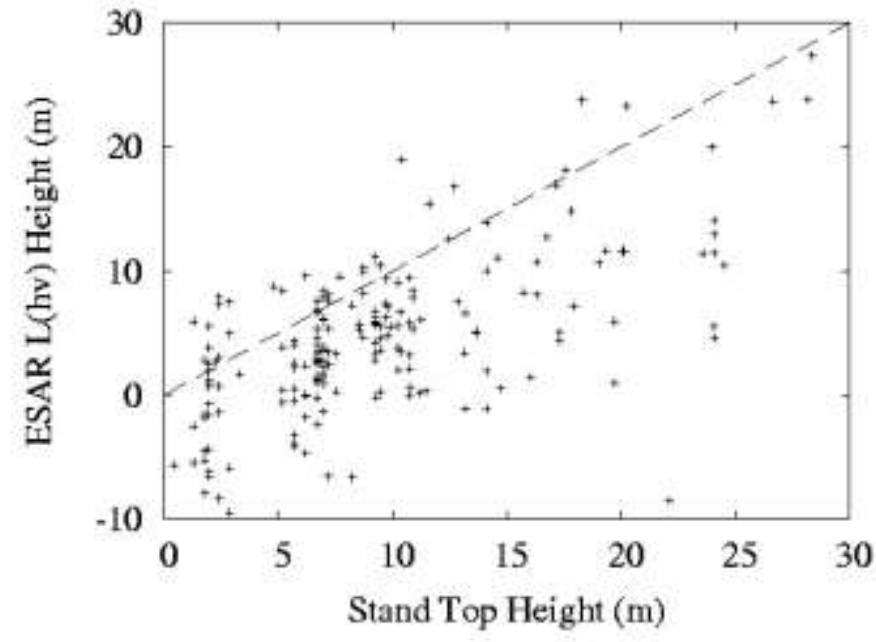

(b)

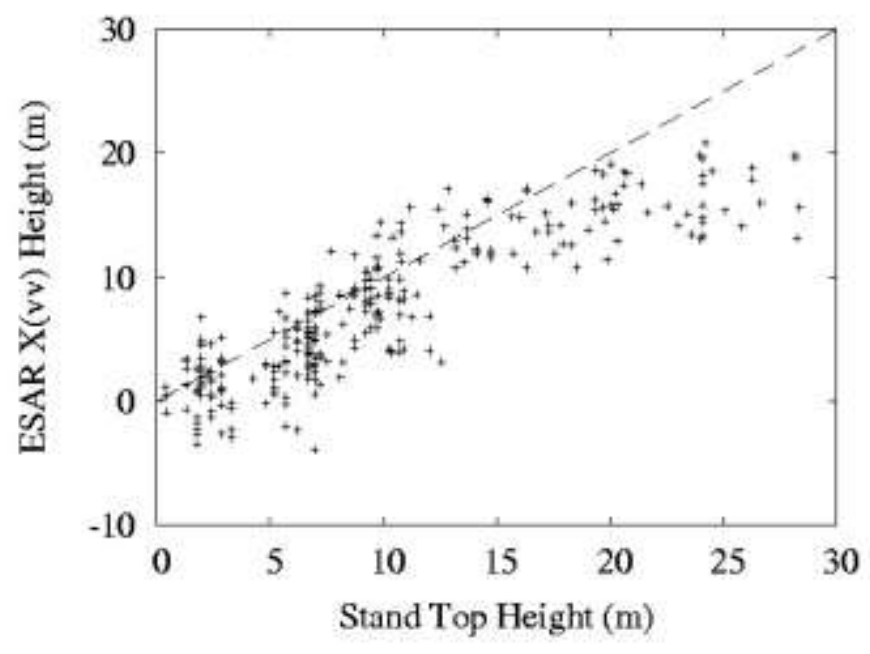

(c)

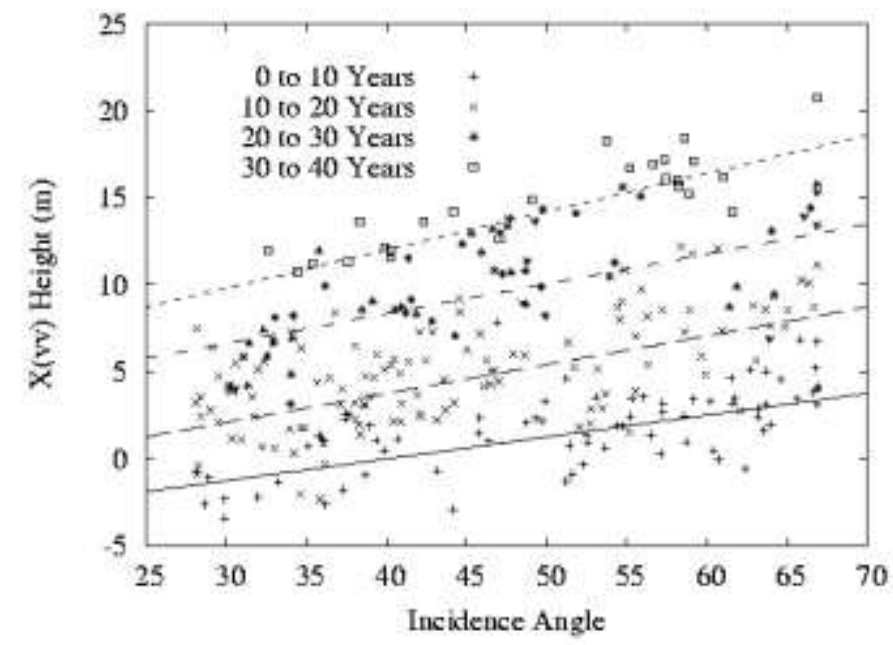

(d)

Figure 6: Plots showing the estimated stand top height from SAR derived over all Corsican Pine stands at Thetford as a function of the stand top height derived from the Forestry Commission GIS database. a) ESAR L(HH), b) L(HV), c) X(VV) scattering phase centre heights, (d) stand top height from ESAR$\mathrm{X}(\mathrm{VV}) \mathrm{DSM}$ and OS DTM as a function of incidence angle for four age groups. The best fit line has been overlaid on top of each plot. 


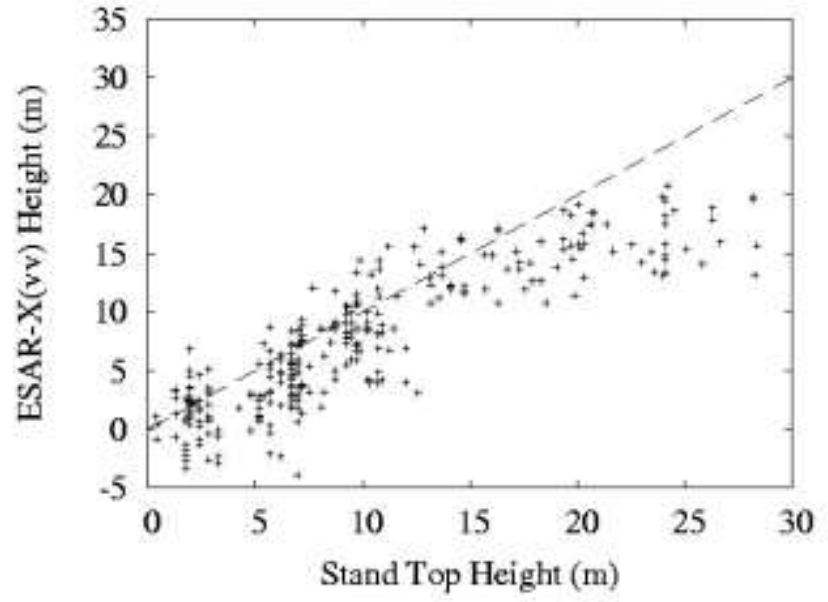

(a)

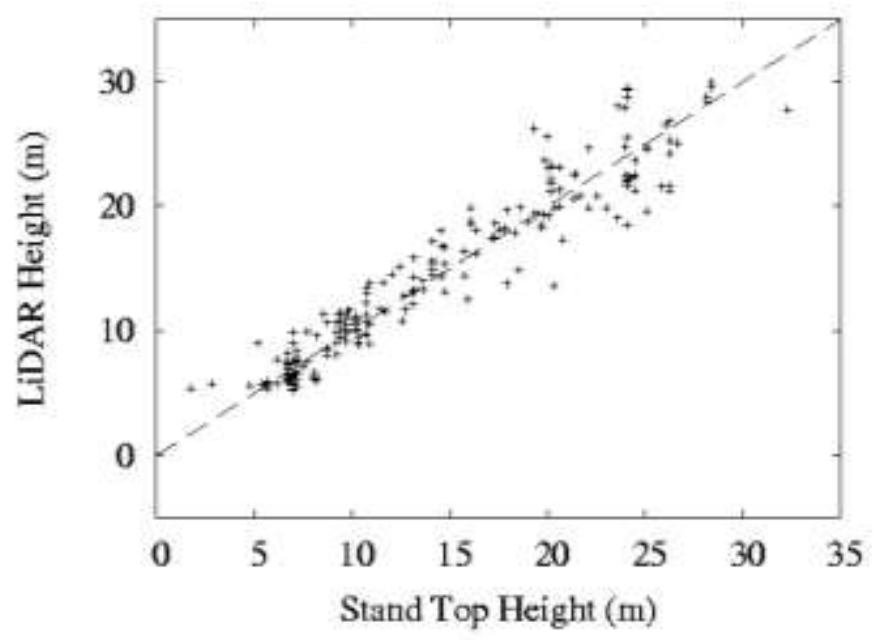

(b)

Figure 7: a) Stand top height derived from the ESAR-X(VV) DSM and OS DTM with a correction for the incidence angle, b) LiDAR estimated stand top height as a function of the stand top height derived from the Forestry Commission GIS database. 


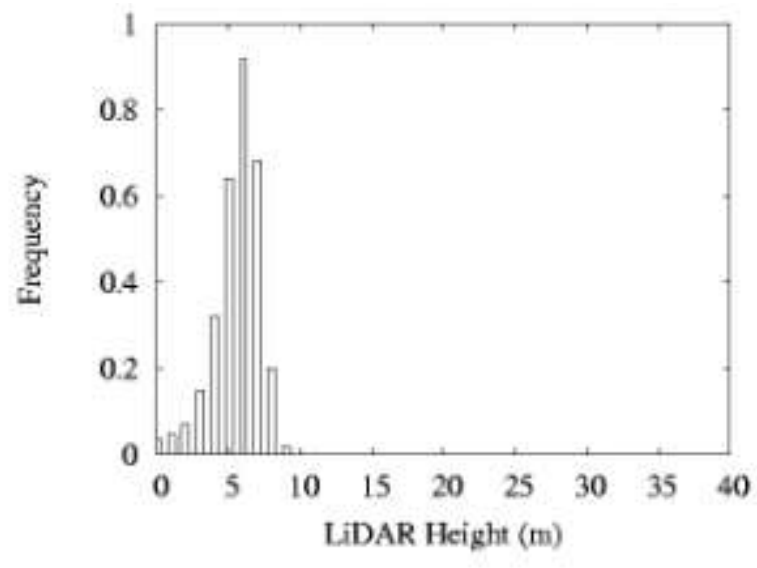

(a)

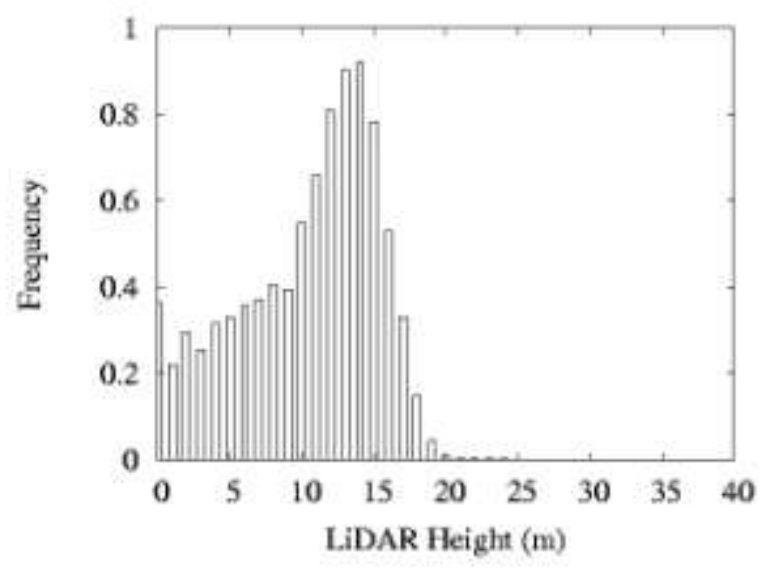

(b)

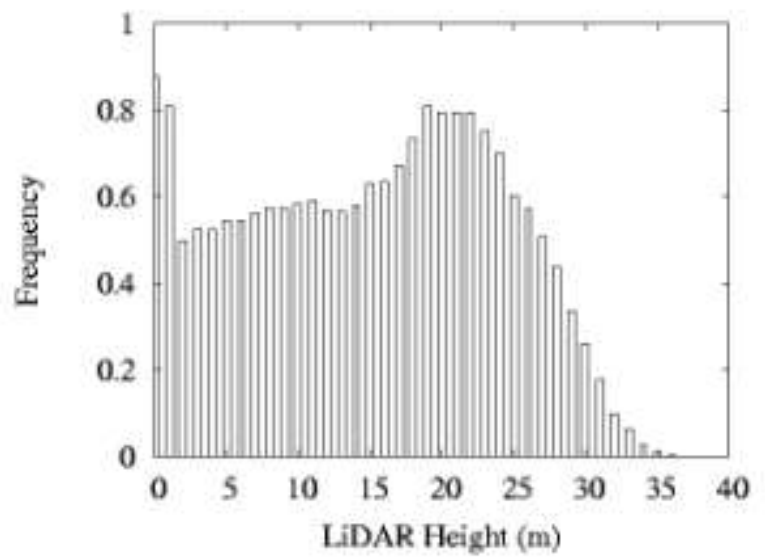

(c)

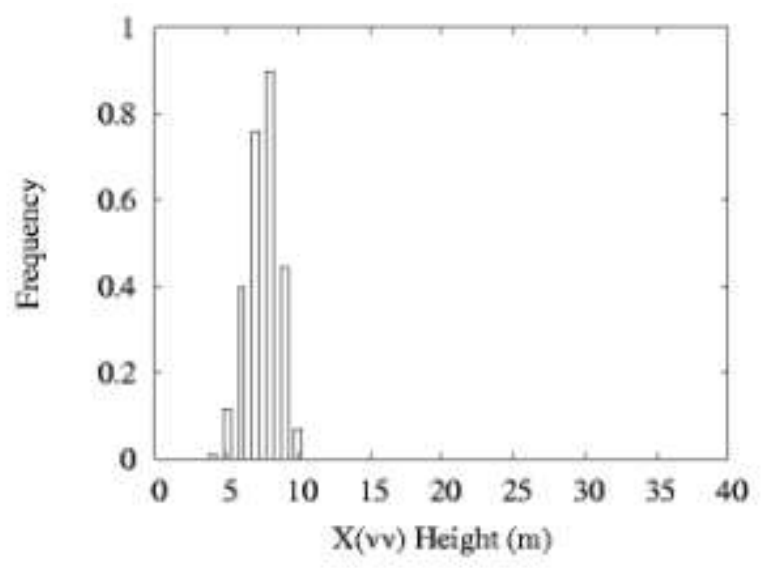

(d)

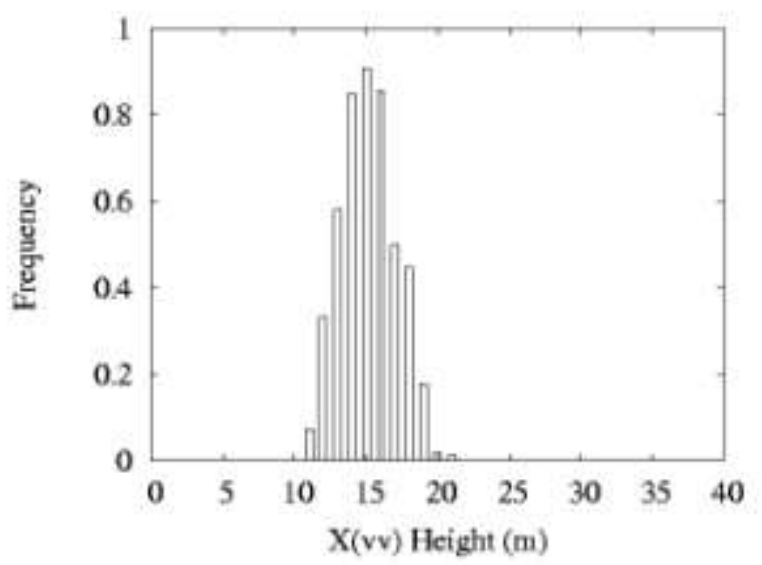

(e)

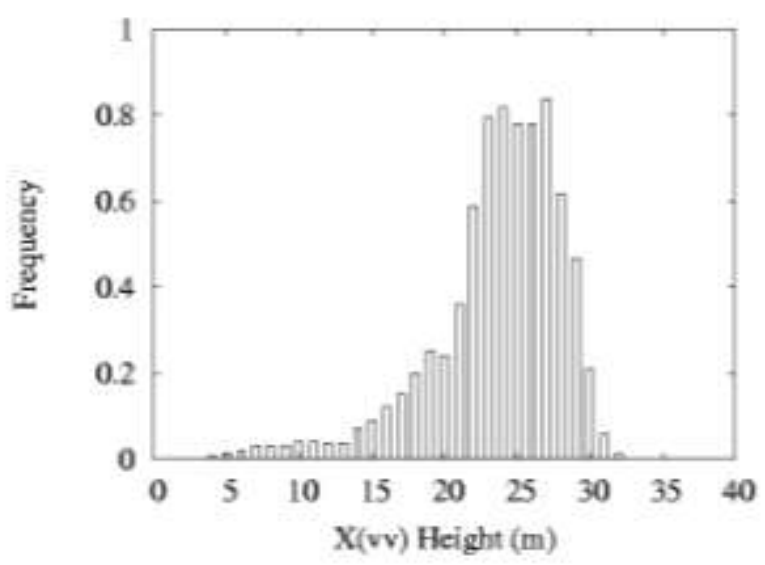

(f)

Figure 8: Histogram plots of height values derived from the LiDAR DSM over Corsican Pine stands aged: a) 16 years, b) 34 years and c) 70 years old. The stands were all located in the near range of the ESAR-X(vv) image. Histograms from the same forest stands based upon the ESAR X(vv) data are shown in $\mathrm{d}$, e and $\mathrm{f}$. 


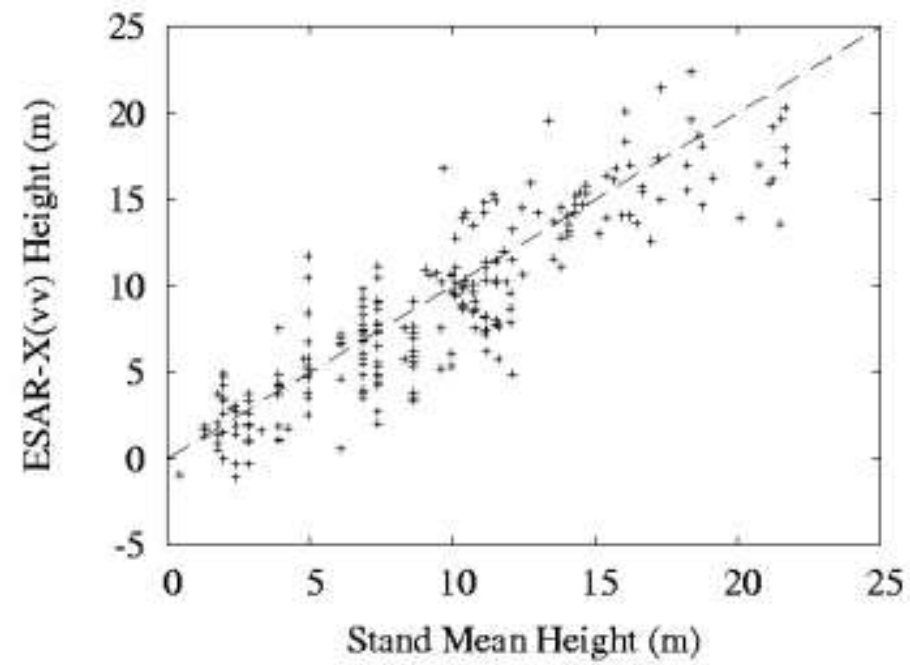

Figure 9: Mean stand height estimated from the ESAR X(VV) data as a function of the predicted mean stand height from the Forestry Commission GIS. 


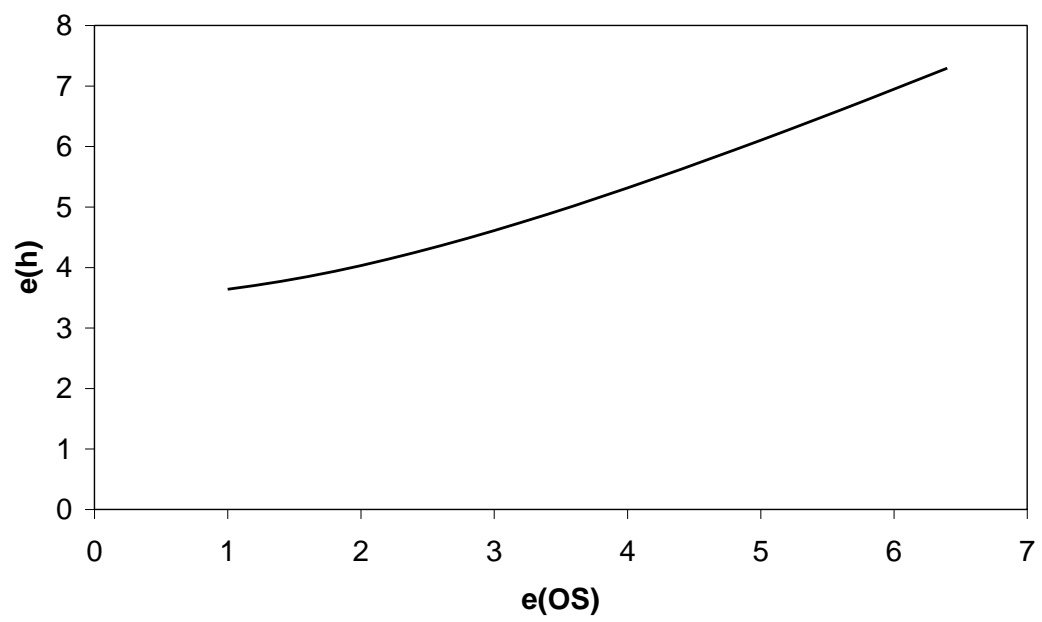

(a)

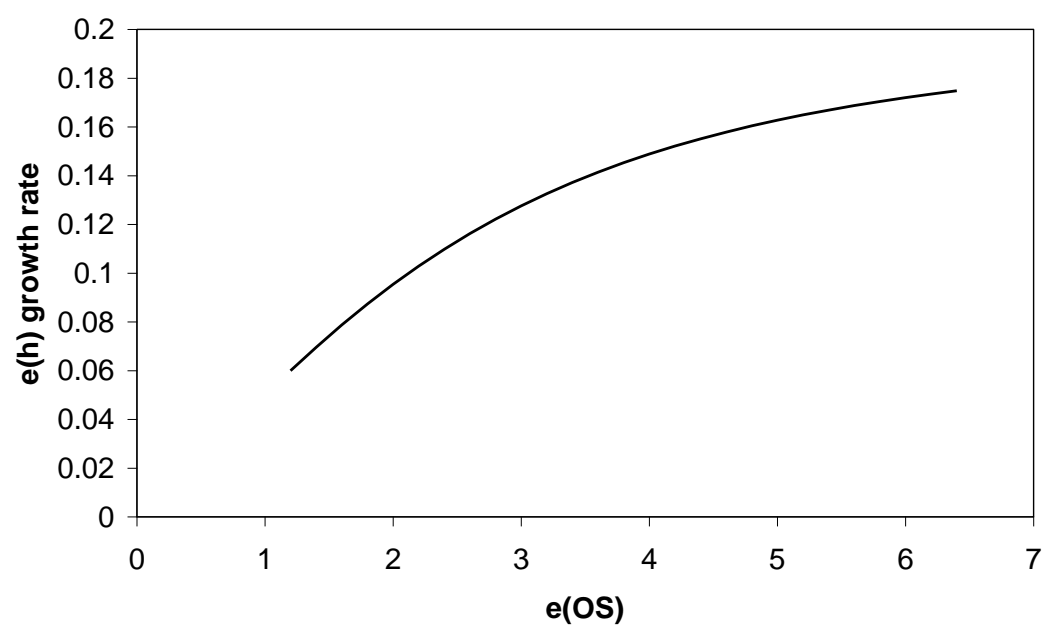

(b)

Figure 10: (a) Modelled error of the estimated canopy height $e(h)$ as a function of an increasing error in the OS-DTM $e(O S)$ under constant error conditions for the remotely sensed elevation estimates $e(R S)=3.5 \mathrm{~m}$ and assuming independent white noise processes. (b) The same error combination model showing the flattening growth rate of $e(h)$ for increasing $e(O S)$.

Table 1: The sensor characteristics of the ESAR and LiDAR sensors.

\begin{tabular}{cccc}
\hline Sensor & ESAR & ESAR & LiDAR \\
\hline Band & X & L & Near IR \\
Frequency $(\mathbf{G H z})$ & 9.6 & 1.3 & 286.3 \\
Polarization & VV & HH, HV , VV & - \\
Pixel Size $(\mathbf{m})$ & $2.50 \times 0.34$ & $2.50 \times 0.88$ & 0.2 to 0.3 \\
Spatial Baseline $(\mathbf{m})$ & 1.5 & 10.2 to 10.5 & - \\
Temporal Baseline & simultaneous & $\sim 15$ minutes & - \\
Incidence angle range $\left({ }^{\circ}\right)$ & $29.8-66.8$ & $25.0-66.8$ & - \\
Swath Width $(\mathbf{k m})$ & 5 & 5 & 0.5 \\
\hline
\end{tabular}


Table 2: The mean coherence, expected height error and accuracy statistics (SDE, rmse and $\mathrm{R}^{2}$ ) for the ESAR X-band DSM and ESAR L-band DSM over bare ground and the OS DTM. The reference ground height was derived from the LiDAR DSM.

\begin{tabular}{|l|c|c|c|c|c|c|c|}
\hline \multicolumn{1}{|c|}{$\begin{array}{c}\text { ESAR } \\
\text { Band }\end{array}$} & $\begin{array}{c}\text { Baseline } \\
(\mathbf{m})\end{array}$ & $\begin{array}{c}\text { Mean } \\
\text { Coherence }\end{array}$ & $\begin{array}{c}\text { Exp. height } \\
\text { error (Near } \\
\text { range) }(\mathbf{m})\end{array}$ & $\begin{array}{c}\text { Exp. height } \\
\text { error (Far } \\
\text { range) (m) }\end{array}$ & $\begin{array}{c}\text { SDE } \\
(\mathbf{m})\end{array}$ & $\begin{array}{c}\text { rmse } \\
(\mathbf{m})\end{array}$ & $\mathbf{R}^{\mathbf{2}}$ \\
\hline $\mathrm{X}(\mathrm{VV})$ & 1.5 & 0.94 & 0.2 & 1.9 & 1.3 & \pm 1.4 & 0.99 \\
\hline $\mathrm{L}(\mathrm{HH})$ & 10 & 0.88 & 0.4 & 4.0 & 4.2 & \pm 4.7 & 0.92 \\
\hline $\mathrm{L}(\mathrm{HV})$ & 10 & 0.93 & 0.5 & 4.9 & 3.8 & \pm 5.2 & 0.94 \\
\hline $\mathrm{L}(\mathrm{VV})$ & 10 & 0.91 & 0.4 & 3.5 & 4.2 & \pm 5.0 & 0.92 \\
\hline OS DTM & - & - & - & - & 1.2 & \pm 1.3 & 0.99 \\
\hline
\end{tabular}

Table 3: The rmse and $\mathrm{R}^{2}$ values for the stand top height estimates derived from the ESAR Lband DSM's in four separate incidence angle ranges. The expected height error for the upper and lower coherence values ( 0.9 and 0.7 respectively) is also shown.

\begin{tabular}{|c|c|c|c|c|c|c|c|c|}
\hline \multirow{2}{*}{$\begin{array}{c}\text { Incidence } \\
\text { angle }\end{array}$} & \multicolumn{2}{|c|}{$\mathbf{L}(\mathbf{H H})$} & \multicolumn{2}{c|}{$\mathbf{L}(\mathbf{H V})$} & \multicolumn{2}{c|}{$\mathbf{L}(\mathbf{V V})$} & $\begin{array}{c}\text { Expected } \\
\text { height error } \\
(\boldsymbol{\gamma}=\mathbf{0 . 9})\end{array}$ & $\begin{array}{c}\text { Expected } \\
\text { height error } \\
(\boldsymbol{\gamma}=\mathbf{0 . 7})\end{array}$ \\
\hline $27-37$ & \pm 3.1 & 0.64 & \pm 3.1 & 0.6 & \pm 3.1 & 0.62 & 0.5 & 1.7 \\
\hline $28-47$ & \pm 4.4 & 0.34 & \pm 4.4 & 0.35 & \pm 4.4 & 0.36 & 0.8 & 2.8 \\
\hline $48-57$ & \pm 5.6 & 0.30 & \pm 5.6 & 0.37 & \pm 5.9 & 0.29 & 1.5 & 4.9 \\
\hline $58-67$ & \pm 6.2 & 0.32 & \pm 6.0 & 0.35 & \pm 6.4 & 0.33 & 2.9 & 9.5 \\
\hline
\end{tabular}

Table 4: The gradient and constant of the best fit linear function fitted to the ESAR X(VV) top height estimates as a function of incidence angle for four age ranges. The mean gradient is also calculated.

\begin{tabular}{|l|c|c|}
\hline \multicolumn{1}{|c|}{ Age Range } & Gradient & Constant \\
\hline 0-10 Years & 0.126 & -5.06 \\
\hline 10-20 Years & 0.166 & -2.90 \\
\hline 20-30 Years & 0.172 & 1.45 \\
\hline 30-40 Years & 0.220 & 3.20 \\
\hline Mean & 0.171 & - \\
\hline
\end{tabular}

